Características odontológicas e prevalência da ardência bucal em doentes com diabetes mellitus do tipo 2

\author{
Dissertação apresentada à Faculdade de \\ Medicina da Universidade de São Paulo para \\ obtenção do título de mestre em Ciências \\ Área de concentração: Neurologia \\ Orientador: Prof. Dr. José Tadeu Tesseroli de \\ Siqueira
}

São Paulo

2009 
Dados Internacionais de Catalogação na Publicação (CIP)

Preparada pela Biblioteca da

Faculdade de Medicina da Universidade de São Paulo

Creprodução autorizada pelo autor

\section{Arap, Astrid Marie Michaluate}

Características odontológicas e prevalência da ardência bucal em pacientes com diabetes mellitus do tipo 2 / Astrid Marie Michaluate Arap. -- São Paulo, 2009.

Dissertação(mestrado)--Faculdade de Medicina da Universidade de São Paulo. Departamento de Neurologia.

Área de concentração: Neurologia.

Orientador: José Tadeu Tesseroli de Siqueira.

Descritores: 1.Diabetes mellitus/etiologia 2.Dor facial 3.Síndrome da boca ardente 4.Neuropatias diabéticas 5.Doenças periodontais

USP/FM/SBD-059/09 


\section{DEDICATÓRIA}

Aos meus pais, Sami e Astrid, pela companhia, por acreditarem e me apoiarem em muitos momentos profissionais, entre tantos outros.

Aos meus irmãos, Marco, Francine, Victor e Denise, pelo incentivo.

Aos meus sobrinhos Victor, Stephanie e Natalie, pela constante alegria. 


\section{AGRADECIMENTOS}

Muitas pessoas me auxiliaram em cada uma das etapas deste trabalho. A todos gostaria de expressar meu agradecimento.

Ao Dr. José Tadeu T. de Siqueira, pelo incentivo, pela confiança e por constantemente nos lembrar do grande valor da Odontologia.

Ao Dr. Claudomiro Barbosa, pela receptividade com que me acolheu no ambulatório de neuropatia diabética e pela grande disponibilidade que sempre demonstrou para ensinar e discutir sobre cada paciente avaliado.

Aos Drs. João Augusto Figueiró e João Carlos Gomes, pelo acolhimento na triagem do Grupo de Dor da Neurologia.

A Dra. Eliane Prado, pela permissão em realizar a avaliação odontológica no Setor de Odontologia da Psiquiatria.

A Dra. Sílvia Siqueira, pela amizade e pelo auxílio com a revisão deste trabalho.

A Dra. Gisele Fabri, pela ajuda nas avaliações periodontais.

Ao Dr. Fabio Kurogi, pelo auxílio na organização da coleta de dados. 
A Dra. Maria Paula Peres, pelo incontestável apoio.

A estatística Creuza Dalbó, pelo auxílio com a análise estatística.

A bibliotecária Rogéria Dias, pelo auxílio com a formatação deste documento.

As Dras. Thais Rolim e Sumatra Jales, pela ajuda na tabulação dos dados e principalmente pela amizade.

A Dra. Valderez Terribili, pelo constante incentivo, pelo conhecimento transmitido e por não desistir.

Aos funcionários da Divisão de Odontologia do HC-FMUSP

Aos pacientes que proporcionaram a realização deste trabalho. 
Esta dissertação está de acordo com as seguintes normas, em vigor no momento desta publicação:

Universidade de São Paulo. Faculdade de Medicina. Serviço de Biblioteca e Documentação. Guia de apresentação de dissertações, teses e monografias. Elaborado por Anneliese Carneiro da Cunha, Maria Julia de A, L. Freddi, Maria F.Crestana, Marinalva de Souza Aragão, Suely Campos Cardoso, Valéria Vilhena. $2^{\mathrm{a}}$ ed.

São Paulo: Serviço de Biblioteca e Documentação; 2005.

Abreviatura dos títulos dos periódicos de acordo com List of Journals Indexed in Index Medicus. 
Lista de abreviaturas

Lista de tabelas

Lista de figuras

Resumo

Summary

1.0 Introdução

1.1 Saúde bucal 2

1.2 Diabetes mellitus 3

1.2.1 Etiologia e prevalência 4

1.2.2 Classificação do Diabetes mellitus 5

1.2.3 Complicações do Diabetes mellitus 6

1.2.4 Neuropatia Diabética $\quad 8$

$\begin{array}{ll}\text { 1.3 Diabetes mellitus e saúde bucal } & 10\end{array}$

1.4 Dor Orofacial 12

1.4.1 Mecanismos neurais das dores orofaciais 13

1.4.2 Epidemiologia das dores orofaciais 18

1.4.3 Classificação das dores orofaciais $\quad 19$

1.4.4 Disfunções temporomandibulares $\quad 20$

1.4.5 Dores neuropáticas orofaciais 23

1.5 Síndrome da Ardência Bucal $\quad 24$

1.5.1 Classificação da SAB 25

1.5.2 Ardor bucal e neuropatia diabética 26 
3.0 Casuística e métodos 29

4.0 Resultados 33

4.1 Características dos doentes com Diabetes mellitus tipo $2 \quad 33$

4.2 Características odontológicas $\quad 35$

4.3 Prevalência e características das dores orofaciais 35

4.4 Avaliação e prevalência de dor e Disfunção temporomandibular (RDC/TMD Eixo 1)

4.5 Avaliação emocional e de incapacidade por dor (RDC/TMD Eixo 2)

4.6 Avaliação da sensibilidade trigeminal

4.7 Avaliação da sensibilidade trigeminal comparativamente entre o grupo de doentes com Diabetes mellitus tipo 2 e o controle

5.0 Discussão 49

6.0 Conclusão 58

Anexos 59

Referências 


$\begin{array}{ll}\text { 5HT } & \text { serotonina } \\ \text { ATM } & \text { articulação temporomandibular } \\ \text { autoAc } & \text { autoanticorpos } \\ \text { AVC } & \text { acidente vascular cerebral } \\ \text { BK } & \text { bradicinina } \\ \text { CGRP } & \text { proteína relacionada ao gene da calcitonina } \\ \text { CPME } & \text { corno posterior da medula espinal } \\ \text { DLP } & \text { dislipidemia } \\ \text { DM } & \text { Diabetes mellitus } \\ \text { DTM } & \text { disfunção temporomandibular } \\ \text { EVA } & \text { escala visual analógica } \\ \text { GABA } & \text { ácido gama-aminobutírico } \\ \text { H } & \text { histamina } \\ \text { HAS } & \text { hipertensão arterial sistêmica } \\ \text { HbA } 1 \text { c } & \text { hemoglobina glicada } \\ \text { IMC } & \text { índice de massa corporal } \\ \text { MMII } & \text { membros inferiores } \\ \text { MMSS } & \text { membros superiores } \\ \text { ND } & \text { neuropatia diabética } \\ \text { NMDA } & \text { n-metil d- aspartato } \\ \text { NO } & \text { óxido nítrico } \\ \text { OMS } & \text { Organização mundial da saúde } \\ \text { PCS } & \text { profundidade clínica de sondagem } \\ \end{array}$


$\mathrm{PCl} \quad$ profundidade clínica de inserção

PG prostaglandina

QST testes quantitativos de sensibilidade

SAB síndrome da ardência bucal

SNC sistema nervoso central

SP $\quad$ substância P

TNF- $\alpha \quad$ fator de necrose tumoral alfa

V1 ramo oftálmico do nervo trigêmeo

V2 ramo maxilar do nervo trigêmeo

V3 ramo mandibular do nervo trigêmeo 
Tabela 1 Distribuição dos doentes avaliados segundo o controle glicêmico e o tempo de tratamento do DM.

Tabela 2 Localização das queixas de neuropatia diabética dos doentes com $\mathrm{DM}(\mathrm{n}=29)$.

Tabela 3 Morbidades associadas encontradas nos doentes com DM $(n=29)$.

Tabela 4 Prevalência de dores e de auto-relatos de bruxismo do sono nos doentes com DM obtidos através da ficha EDOF-HC $(n=29)$.

Tabela 5 Número de descritores e índice de dor de acordo com o questionário Mcgill de avaliação de dor.

Tabela 6 Características da dor orofacial nos doentes com DM 2.

Tabela 7 Distribuição dos doentes quanto ao diagnóstico de dor na musculatura mastigatória de acordo com o questionário RDC/TMD Eixo 1.

Tabela 8 Diagnóstico de anormalidades da articulação temporomandibular (ATM) de acordo com o questionário RDC/TMD Eixo 1. 
Tabela 9 Características da mobilidade mandibular (RDC/TMD Eixo 1) nos doentes com DM $(n=29)$.

Tabela 10 Comparação das algiometrias do $\mathrm{V}$ par craniano entre os doentes com DM, respectivamente com e sem dor orofacial $(n=29)$.

Tabela 11 Algiometria do território trigeminal dos doentes com DM ( $n=29)$.

Tabela 12 Correlação entre glicemia, $\mathrm{HbA}_{1 c}$ e algiometria dos doentes com DM.

Tabela 13 Correlação entre as algiometrias de V1, V2 e V3 nos doentes com DM. 
Figura 1 - Distribuição dos doentes segundo a limitação da função mandibular (RDC/TMD Eixo 1).

Figura 2 - Distribuição dos doentes segundo o grau de dor crônica e incapacidade. (RDC/TMD Eixo 2).

Figura 3 - Distribuição dos doentes segundo a presença de traços de depressão (RDC/TMD Eixo 2).

Figura 4 - Distribuição dos doentes quanto a presença de sintomas físicos inespecîficos (RDC/TMD Eixo 2).

Figura 5 - Avaliação da algiometria trigeminal comparativamente entre o grupo de estudo (DM) e o grupo controle.

Figura 6 - Boxplot para comparação entre a algiometria de V2 lado direito entre os grupos de estudo e controle. 


\section{RESUMO}

Arap AMM. Características odontológicas e prevalência da ardência bucal em doentes com Diabetes mellitus do tipo 2 [dissertação]. São Paulo: Faculdade de Medicina, Universidade de São Paulo; 2009. 84p.

O Diabetes mellitus (DM) é o transtorno endócrino mais comum e afeta $6 \%$ da população mundial. A neuropatia diabética é uma das complicações do DM e acomete até $60 \%$ dos doentes diabéticos. Este é um estudo descritivo que teve como objetivo avaliar as condições odontológicas e a prevalência da ardência bucal nos doentes diabéticos tipo 2 com neuropatia diabética. Foram utilizados os seguintes instrumentos de avaliação: exame sensitivo padronizado da face (algiometria), questionário RDC/TMD eixos 1 e 2, (critérios de diagnóstico em pesquisa) para o diagnóstico de disfunção temporomandibular (DTM), protocolo de avaliação de dor orofacial (EDOF-HC), questionário McGill para avaliação de dor e exame periodontal (IS - índice de sangramento, PCS - profundidade clínica de sondagem, $\mathrm{PCl}$ - profundidade clínica de inserção). A prevalência de dor orofacial foi $55,2 \%$ e de ardor bucal foi $17,2 \%$. Os valores de glicemia em jejum e $\mathrm{HbA}_{1 \mathrm{c}}$ apresentaram-se acima dos valores normais. Dos doentes avaliados, $44,8 \%$ eram totalmente desdentados, $41,2 \%$ dos doentes apresentaram doença periodontal avançada, prevalência de dor miofascial mastigatória foi $31 \%$. Traços de depressão moderada e grave e de sintomas físicos inespecíficos moderados e graves foram encontrados em $51,7 \%$ dos doentes, de incapacidade baixa e moderada em 37,9\%. Observou-se comprometimento da sensibilidade dolorosa em V2 lado $D(p=0,007)$, correlacionada com os valores de $\mathrm{HbA}_{1 \mathrm{c}}$.

Descritores: Diabetes mellitus - dor orofacial - síndrome da ardência bucal neuropatia diabética. 


\section{SUMMARY}

ARAP AMM. Dental characteristics and burning mouth prevalence in type 2 Diabetes mellitus patients. [dissertation]. "Faculdade de Medicina, Universidade de São Paulo"; 2009. 84p.

Diabetes mellitus (DM) is one of the most common metabolic diseases affecting $6 \%$ of the world population. Diabetic neuropathy is one of DM complications and it affects up to $60 \%$ of diabetic patients. This descriptive study aimed to evaluate the dental characteristics and burning mouth prevalence of type 2 DM patients. The following instruments were used: pain sensory test, RDC/TMD questionnaire axis 1 and 2 (research diagnostic criteria for temporomandibular disorders), EDOF-HC protocol (for orofacial pain), Mcgill's pain questionnaire and periodontal evaluation (bleeding index, clinical probing depth, clinical probing insertion). Orofacial pain was found in $55,2 \%$ of the patients, burning mouth was found in $17,2 \%$. Fasting blood glucose and $\mathrm{HbA}_{1 \mathrm{c}}$ levels were found to be higher than the recommended. $44,8 \%$ of the patients were totally edentulous, severe periodontal disease prevalence was $41,2 \%$. Masticatory myofascial pain was found in $31 \%$ of the evaluated patients. Traces of severe and moderate depression and severe and moderate nonspecific physical symptoms were found in $51,7 \%$ of the patients; moderate and low disability in $37,9 \%$. There was significative difference in the algometry values of the V2 right side compared to the left side and to the study group $(p=0,007)$, with positive correlation with the increased values of the $\mathrm{HbA}_{1 \mathrm{c}}$.

Descriptors: Diabetes mellitus - orofacial pain - burning mouth syndrome diabetes neuropathy. 


\subsection{INTRODUÇÃO}

O Diabetes mellitus (DM) é o transtorno endócrino mais comum, caracterizado pela anormalidade no metabolismo de carboidratos, lipídios e proteínas e resultante da deficiência grave ou absoluta de insulina, ou ainda da resistência dos órgãos alvo aos efeitos celulares deste hormônio (Vernillo, 2001).

No mundo, o DM afeta $6 \%$ da população, o que significa mais de 100 milhões de pessoas. No Brasil, em 2000, o número de diabéticos era de 4,6 milhões e estima-se que em 2030 aumente para 11,3 milhões de pessoas, ou seja, em 30 anos espera-se um aumento de 148,3\% (Adeghate et al., 2006).

As complicações metabólicas do DM, normalmente mais graves nos indivíduos com DM tipo 1, incluem maior susceptibilidade a infecções, atraso no processo de reparação tecidual, neuropatias, nefropatia, retinopatia e doenças micro e macrovascular (Vernillo, 2001).

A neuropatia diabética está entre as complicações mais comuns e atinge até $60 \%$ dos doentes. Os sintomas são mais pronunciados em membros inferiores e podem ser dolorosos (queimação, choque) ou não (formigamento, anestesia) (Spruce et al, 2003; Boulton, 2005). Pode também acometer nervos cranianos e nestes casos, o nervo oculomotor é o mais afetado (Kelkar, 2005). 
Um amplo espectro de manifestações orais do DM já foi relatado: xerostomia, alterações do paladar e perda da sensibilidade, ardor bucal, cáries dentárias, doença periodontal e infecções fúngicas (Manfredi et al., 2004). As neuropatias também constituem fator de risco para a perda dental e para a disfunção temporomandibular em doentes idosos com DM tipo 2 (Shinkai et al., 2004).

As alterações do paladar e as disfunções sensitivas podem sugerir alterações neuropáticas, primárias como na Síndrome da ardência bucal (SAB), ou secundárias a doenças crônicas, ou condições sistêmicas, que originariam neuropatias periféricas (Nasri et al., 2007).

\subsection{SAÚDE BUCAL}

Saúde bucal significa não apenas ter dentes e gengivas sadias. Significa estar livre de dores crônicas e outras doenças que acometem o aparelho mastigatório. Implica na possibilidade de uma pessoa exercer plenamente funções como mastigação, deglutição e fonação, exercitar a autoestima e relacionar-se socialmente sem inibição ou constrangimento, o que contribuirá para sua saúde geral (Petersen, 2003).

Particularmente a doença periodontal merece atenção por ser doença infecciosa e ter inúmeras implicações sistêmicas. Dados epidemiológicos revelam alta prevalência da doença periodontal na população adulta em geral 
e claro aumento da prevalência com a idade (Löe et al., 1978; Albandar, Rams, 2002). Levantamento epidemiológico populacional sobre saúde bucal, realizado pelo Ministério da Saúde, entre 2002-2003, a porcentagem de pessoas sem problema periodontal, nas faixas etárias de 15 a 19, 35 a 44 e 65 a 74 anos de idade, foi, respectivamente, $46,2 \%, 21,9 \%$ e $7,9 \%$. A porcentagem de pessoas com bolsas periodontais maiores que $4 \mathrm{~mm}$ foi de $1,3 \%, 9,9 \%$ e $6,3 \%$, respectivamente nas mesmas faixas etárias acima citadas. Com a idade eleva-se o número de dentes perdidos, e na faixa etária de 65 a 74 anos mais de $80 \%$ dos sextantes examinados eram desdentados ou apresentavam apenas um dente funcional (Projeto SB Brasil, 2003).

\subsection{DIABETES MELLITUS (DM)}

Segundo a Associação Americana de Diabetes, o Diabetes mellitus (DM) é um conjunto de doenças metabólicas caracterizada por hiperglicemia resultante de defeitos na secreção da insulina, na sua ação ou em ambos os casos. Essa hiperglicemia crônica está associada a disfunções e falência de alguns órgãos, especialmente dos rins, coração, tecido nervoso, tecido vascular e olhos. Diversos processos patogênicos, que variam desde a destruição auto-imune das células $\beta$ pancreáticas até anormalidades que resultam na resistência à insulina, estão envolvidos no desenvolvimento do DM (ADA, 2007). 


\subsubsection{Etiologia e prevalência}

A etiologia multifatorial, envolvendo fatores genéticos e ambientais, é mais aceita atualmente para o DM. A freqüência de doentes diabéticos com história familiar positiva varia de $25 \%$ a 50\% (Adeghate et al., 2006).

O DM é uma das doenças metabólicas mais comuns, e afeta quase $6 \%$ da população mundial (Adeghate et al., 2006). Sua prevalência ainda cresce decorrente do aumento e envelhecimento da população, urbanização, aumento dos casos de obesidade e inatividade física. Estima-se que o número total de doentes diabéticos alcance 366 milhões em 2030, a faixa etária mais acometida seja dos 45 aos 64 anos (Wild et al., 2004) e cerca de $97 \%$ dos casos será do tipo 2. Este tipo de diabetes tem predominância discretamente maior em mulheres que em homens, e é mais comum em áreas urbanas do que nas rurais (Adeghate et al., 2006).

Na América do Sul, a prevalência do DM tipo 2 varia de acordo com região e pais, o Brasil é o que apresenta maior prevalência $(2,7 \%-17,4 \%)$, particularmente em áreas urbanas como São Paulo (12,1\%) (Adeghate et al., 2006). Coronho et al (2001) relataram 5 milhões de pessoas no Brasil com DM e a estimativa para o ano de 2030 é de 11,3 milhões (WIld et al., 2004). O DM tem altos índices de morbidade e de mortalidade, sendo responsável por cerca de 40 mil mortes ao ano (Vernillo, 2001). 


\subsubsection{Classificação do Diabetes mellitus}

Designar um tipo específico de DM para o indivíduo depende de suas circunstâncias no momento do diagnóstico e nem sempre as pessoas encaixam-se em uma única classe (ADA, 2007).

O DM tipo 1 ou diabetes imunomediado responde somente por 5 a $10 \%$ dos casos e tem início antes dos 30 anos de idade. Previamente denominado diabetes insulino dependente ou diabetes juvenil, resulta da destruição celular auto imune das células $\beta$ pancreáticas. Essa destruição é variável e pode ocorrer rapidamente (em crianças) ou mais lentamente (em adultos) (ADA, 2007; Manfredi et al., 2004).

A destruição auto-imune apresenta predisposições genéticas e influência ambiental, estas ainda pouco esclarecidas. Os marcadores imunológicos incluem autoAc à insulina e autoAc às células da ilhota. Os doentes com DM tipo 1 têm mais propensão à outras doenças auto imunes, tais como a doença celíaca, doença de Addison, miastenia grave, tireodite de Hashimoto, hepatite auto imune e anemia perniciosa. (ADA, 2007).

Segundo White et al., 2003, o DM tipo 2 é caracterizada por hiperglicemia crônica causada por defeitos na secreção de insulina (função deficiente na célula B) e na sua ação (resistência insulínica pelo fígado e tecido muscular). Esses defeitos ocorrem precocemente no curso da doença e estão presentes antes do diagnóstico. Este tipo de DM produz ou contribui para a alta morbidade das complicações metabólicas. Estratégias agressivas 
de tratamento devem ser utilizadas para o estrito controle glicêmico. Estas estratégias incluem o uso precoce da insulina, sozinha ou combinada com outros agentes hipoglicemiantes.

O valor considerado normal da glicemia em jejum é $<100 \mathrm{mg} / \mathrm{dL}$. O diagnóstico de DM (deve ser confirmado com teste de tolerância a glicose) será dado quando a glicemia for $>126 \mathrm{mg} / \mathrm{dL}$. O valor ideal de $\mathrm{HbA}_{1 \mathrm{c}}$ varia de $4 \%$ a $7 \%$ (White et al., 2003; ADA 2007).

\subsubsection{Complicações do Diabetes mellitus}

A hiperglicemia é a conseqüência metabólica imediata do DM, porém ocorre também um dano multissistêmico difuso, particularmente microvascular. Todas as formas de DM são caracterizadas por hiperglicemia, avaliada durante o teste de tolerância à glicose por via oral. Os testes de glicemia em jejum e de tolerância à glicose alteradas são usadas para indicar um estado metabólico intermediário entre a normalidade da homeostase da glicose e a condição de Diabetes mellitus (Manfredi et al., 2004).

As complicações metabólicas crônicas são, normalmente, mais graves nos doentes com DM tipo 1, e são as seguintes: maior susceptibilidade a infecções, atraso no processo de cicatrização, neuropatia, retinopatia, nefropatia (doença microvascular), aterosclerose acelerada, associada à infarto agudo do miocárdio, acidente vascular cerebral (AVC), aneurismas ateroscleróticos (doença macrovascular) e amputação. (Vernillo, 2001). 
A doença macrovascular afeta $20 \%$ dos doentes com DM tipo 2 e constitui a principal causa de morte nestes indivíduos. As complicações microvasculares estão presentes em 30 a $45 \%$ dos diabéticos tipo 2. Fatores de risco conhecidos para estas complicações incluem controle glicêmico precário, duração da doença, HAS e DLP. A síndrome metabólica, caracterizada pela presença de dois ou mais dos seguintes fatores: HAS, obesidade, DLP, microalbuminuria (associada a resistência à insulina), também constitui fator de risco para doença cardiovascular (Costa et al., 2004).

Estudos demonstram que a obesidade generalizada favorece o risco de desenvolvimento de DM tipo 2 por induzir resistência a insulina. Esse risco é diretamente associado ao aumento do Índice de Massa Corporal (IMC). O IMC é um método de avaliação do estado nutricional de adultos e idosos a partir do peso e da altura. O quadro abaixo mostra a classificação nutricional segundo o IMC (Marques et al., 2007).

Classificação (OMS)

Abaixo do peso

Faixa normal

Sobrepeso

Pré-obesidade

Obesidade grau I

Obesidade grau II

Obesidade grau III
IMC $\left(\mathrm{Kg} / \mathrm{m}^{2}\right)$

$$
<18,5
$$

$18,5-24,9$

$\geq 25$

$25-29$

$30-34,9$

$35-39,9$

$\geq 40$ 
As complicações do DM decorrem principalmente da duração e gravidade da hiperglicemia, cujos sinais e sintomas mais freqüentes são: poliúria, polidipsia, polifagia, fadiga, perda de peso; essas queixas ocorrem principalmente no início da doença em doentes jovens, quando ocorre profunda deficiência de insulina (Vernillo, 2001).

\subsubsection{Neuropatia diabética (ND)}

De acordo com Boulton (2005), a ND é definida como a presença de sinais ou sintomas de disfunção nervosa periférica em doentes diabéticos, após a exclusão de outras causas. Está entre as complicações mais comuns e atinge cerca de $50 \%$ dos doentes diabéticos. É dividida em dois principais grupos: a neuropatia sensitiva aguda e neuropatia sensitivomotora crônica. A primeira tem aparecimento agudo com sintomas sensitivos graves (dor em queimação e alodínea) e sem alterações motoras, pode ter início com episódio de instabilidade glicêmica e a melhora gradual dos sintomas ocorre com tratamento sintomático apropriado e controle da glicemia. A neuropatia crônica é uma das complicações mais debilitantes do DM. Muitos doentes são assintomáticos e o déficit é descoberto em exame de rotina. As manifestações sensitivas são mais pronunciadas em membros inferiores e em casos mais graves pode atingir as mãos e dedos. Os sintomas podem ser dolorosos (queimação, congelante, choque) ou não (formigamento, adormecimento, anestesia) e são constantes. Pode ocorrer falta de firmeza nos membros, os reflexos calcâneos encontram-se diminuídos ou ausentes. O tratamento inclui 
o uso de tricíclicos, anticonvulsivantes, tratamento tópico com capsaicina e opióides, uma vez que não há restauração da função neuronal, o tratamento farmacológico baseia-se no controle dos sintomas dolorosos (Spruce et al., 2003).

A ND manifesta-se como diferentes síndromes clínicas. Diversos mecanismos fisiopatológicos contribuem e podem agir simultaneamente para seu aparecimento, incluindo alterações metabólicas, vasculares e inflamatórias (Kelkar, 2005). Associados a isso, a glicemia e insulinemia, idade do doente e duração do DM, álcool, tabagismo e albuminúria são fatores de risco para seu desenvolvimento (Gagliardi, 2003). A redução dos valores de $\mathrm{HbA}_{1 c}$ diminui a incidência de complicações, inclusive da ND. Esta mostrou-se presente em $60 \%$ dos casos quando a $\mathrm{HbA}_{1 \mathrm{c}}$ esteve maior que 7\% (Vernillo, 2001).

A neuropatia periférica em DM tipo 2 mostrou-se mais freqüente em doentes com síndrome metabólica e teve aumento proporcional e associado às anormalidades metabólicas (Costa et al., 2004).

Nos últimos 20 anos, diversas teorias foram propostas para explicar a fisiopatologia da ND. A hiperglicemia persistente leva ao acúmulo de produtos da via dos polióis (sorbitol e frutose) no tecido nervoso. A partir daí ocorre uma diminuição no tamponamento contra a oxidação, inibição do relaxamento vascular e por fim isquemia crônica (Gagliardi, 2003; Kelkar, 2005). A microvasculopatia inflamatória é evidência crescente de que as neuropatias 
assimétricas são causadas por vasculopatias inflamatórias ou vasculites. O tecido nervoso no diabético tem susceptibilidade aumentada aos fatores imunes celulares e humorais, incluindo a ativação de linfócitos, deposição de imunoglobulinas e ativação do sistema complemento. $O$ acúmulo dos produtos finais da glicação interfere no transporte axonal, diminuindo a velocidade de condução nervosa. A deficiência de insulina e de fatores de crescimento, que contribuem para a função, reparação e manutenção da estrutura nervosa, contribuem para o desenvolvimento da ND. Anormalidades nos canais iônicos de cálcio e sódio da membrana neuronal também tem papel na gênese neuropatia (Kelkar, 2005).

\subsection{DIABETES MELLITUS E SAÚDE BUCAL}

Diversas alterações decorrentes do DM têm impacto na saúde bucal. Um fluxo salivar adequado é crucial para manter conforto e uma condição de saúde. Com a redução salivar pode-se esperar um impacto negativo nas cáries dentárias e em outras infecções, além da redução da capacidade tampão e da atividade antimicrobiana. A xerostomia é freqüente queixa entre os indivíduos diabéticos e pode decorrer diretamente do DM, de doenças comumente associadas a ela como, por exemplo, a hipertensão arterial ou da medicação utilizada no tratamento destas afecções (Dodds et al., 2000). 
Atualmente, é aceito que as neuropatias diabéticas e as alterações na microcirculação causam mudanças na cavidade oral. A doença periodontal é considerada uma complicação do DM e há evidências de que o controle da infecção periodontal leva à um melhor controle metabólico pela redução do TNF- $\alpha$, o que diminui o valor do $\mathrm{HbA}_{1 c}$ (Mealey, Rose, 2008). São queixas freqüentes dos doentes diabéticos a diminuição do fluxo salivar, alteração da composição da saliva, perda de sensibilidade, inflamação, mudanças do paladar, adormecimento, síndrome da ardência bucal e lesões em língua e mucosa oral. As neuropatias periféricas e autonômicas também constituem fatores de risco independentes para perda dental e disfunção temporomandibular em doentes idosos com DM tipo 2, porém a doença não interfere na sensibilidade intraoral (Shinkai et al, 2004).

Manfredi et al, 2004 relatam um largo espectro de manifestações bucais em doentes com DM. A xerostomia em doentes com DM tipo 1 está relacionada ao controle glicêmico e em doentes com o tipo 2 está ligada ao uso de drogas xerogênicas e à neuropatia autonômica; a diminuição do paladar pode sugerir alteração nestes receptores. A maior propensão dos diabéticos à cárie pode refletir maiores concentrações de glicose na saliva, porém a maioria deles desenvolve cárie por higiene oral precária. $\mathrm{O}$ autor também relata maior propensão a infecções fúngicas superficiais e sistêmicas e ao aparecimento do líquen plano, principalmente na sua forma erosiva. 
Mealey, Rethman (2003) relataram que a Associação Americana de Periodontia publicou a evidência da periodontite agravada pelo DM em comparação aos indivíduos que não o tem. Qualquer aumento no risco de desenvolvimento da doença periodontal em DM pode ser influenciado pela redução na proliferação e crescimento celular e síntese de colágeno e glicosaminoglicanas, eventos associados à hiperglicemia (Manfredi et al., 2004).

\subsection{DOR OROFACIAL}

Genericamente, a denominação Dor Orofacial refere-se às condições álgicas relacionadas às estruturas da cavidade oral e da face propriamente dita.

De acordo com a Academia Americana de Dor Orofacial, o campo de atuação nessa área inclui as condições álgicas decorrentes dos diferentes tecidos da cabeça e do pescoço, incluindo todas as estruturas que formam a cavidade oral (Okeson, 1996; AAOP, 2008). São múltiplas as origens de dores orofaciais e ocorrem em diferentes áreas da cabeça e do corpo humano, envolvendo disciplinas médicas ou odontológicas, exigindo frequentemente treinamento e abordagem interdisciplinar (Blasberg, Greenberg, 2003, Okeson, 2006). 
Os estudos que investigam dores orofaciais crônicas demonstram que os doentes apresentam, freqüentemente, alterações neurais e emocionais; parecem ter também maior susceptibilidade à dor músculo-esquelética, apresentando, com maior freqüência, queixa de dores em várias partes do corpo (Ren, Dubner, 2002; John et al., 2003, Camparis, Siqueira, 2006). A dor aguda é associada a condições clínicas de início recente, que cessam com o tratamento da causa. Quanto às dores crônicas, têm diversas origens e nem sempre cessam com a eliminação da causa e, atualmente, utiliza-se o critério temporal (acima de seis meses) para caracterizá-la (Merskey, Bogduk, 1994).

\subsubsection{Mecanismos neurais das dores orofaciais}

Sob o aspecto neuroanatômico, no segmento cefálico destaca-se o complexo trigeminal por ser o principal responsável pela sensibilidade da região. A enorme convergência neuronal para o núcleo do trato espinal do nervo trigêmeo seja da face ou do crânio, conduzida pelos nervos trigêmeo, facial, glossofaríngeo e vago respondem, em parte, pela complexidade das dores crânio-faciais, sob o aspecto clínico (Sessle, 2005).

Resumidamente, os mecanismos periféricos e centrais das dores orofaciais podem ser apresentados do seguinte modo (Hu et al., 1997; Teixeira, 2001; Sessle, 2005):

Componentes periféricos: incluem as terminações nervosas livres (Adelta e C); os mediadores da inflamação, a exemplo da bradicinina (BK), da histamina $(\mathrm{H})$, da prostaglandina (PGE) e da serotonina $(5 \mathrm{HT})$; e os 
neurotransmissores, como a substância $\mathrm{P}(\mathrm{SP})$, o peptídeo relacionado ao gene da calcitonina (CGRP) e a serotonina (5HT). A intensidade do estímulo nociceptivo e a sua resposta inflamatória determinam a extensão da lesão. Os estímulos nociceptivos alcançam as terminações nervosas e há transdução do estímulo, que será conduzido pelas vias nervosas. No local da lesão ocorre, portanto, uma sensibilização das terminações nervosas conhecida como sensibilização periférica, onde há redução do limiar de percepção de dor (hiperalgesia). Este é um importante fenômeno na geração da dor e na sua própria manutenção, pois a complexidade dos componentes envolvidos, de acordo com a intensidade do estímulo, gera fenômenos como da inflamação neurogênica que alastram a dor, espalhando-a pelas adjacências da área atingida.

Componentes centrais: a região do tronco encefálico recebe as informações de face e crânio, particularmente a informação sensitiva é realizada pelo sistema nuclear trigeminal. Como em qualquer outra condição álgica, o tálamo e o córtex cerebral participam ativamente na modulação da informação dolorosa. Por essas áreas passarão os estímulos provenientes de boca, face e da duramáter. A conexão dessas estruturas com o sistema neurovegetativo (simpático e parassimpático) explica muitas das manifestações clínicas globais, como: taquicardia, náusea e aumento de pressão sanguínea periférica. Além disso, a sensibilidade da face também é realizada pelos nervos: facial, glossofaríngeo, vago e cervicais superiores, que aumenta a complexidade dessa região, no que diz respeito à ocorrência 
de dor. A convergência neuronal ampla de toda a região (face e crânio) para o núcleo do trato espinal do trigêmeo justifica, em parte, o fenômeno da dor referida nesse segmento do corpo humano. A estrutura laminar do subnúcleo caudal do trato espinal do trigêmeo tem características próprias, apesar de ser a continuidade do corno posterior da medula. Nele ocorre a modulação da dor orofacial e a conexão com os neurônios de segunda ordem. Mediadores químicos envolvidos na transmissão dolorosa, como o glutamato e a substância $P$, excitatórios, e seus receptores, como o NMDA (n-metil daspartato), e moduladores inibitórios da dor como a serotonina, encefalina e GABA, predominam nessa região, em comparação com outras do sistema trigeminal. Marcadores da atividade neuronal, como a proteína c-Fos, são predominantemente aí encontrados.

Modulação da transmissão nociceptiva: o resumo apresentado no ítem anterior explica, em parte, a presença de relês que modulam a intensidade da dor orofacial no sistema nervoso central (SNC). Existem projeções descendentes inibitórias do SNC que modulam a atividade no sistema nuclear trigeminal, além da presença de interneurônios inibitórios. A região cinzenta periaquedutal contém corpos celulares de neurônios que recebem estímulos dos centros superiores e projetam-se para regiões rostrais da medula, e estão envolvidos com a inibição da dor. Por exemplo, o reflexo de abertura da boca e algumas atividades nociceptivas orofaciais, são moduladas por várias regiões do tronco encefálico e por centros superiores, como região periaquedutal, medula rostral ventromedial e córtex sensório-motor. Estudos 
antigos mostram que a dor pulpar experimental é modulada nessas áreas do cérebro. Entender minimamente estes aspectos contribui para a aplicação de terapêuticas anti-álgicas na atividade clínica, evitando abordagens repetitivas na região operada.

Neuroplasticidade: a intensidade e a freqüência do estímulo nocivo decorrente do traumatismo e da inflamação dos tecidos periféricos, como é o caso das cirurgias na cavidade oral, alteram e excitam a atividade no SNC, particularmente nas áreas citadas nos itens anteriores. Essas alterações centrais são morfológicas, bioquímicas e funcionais. Elas contribuem para a expansão dos campos receptores dos neurônios nociceptivos cutâneos, aumentando sua atividade espontânea, elevando sua resposta ao estímulo irritante e reduzindo o limiar de tolerância aos estímulos na região afetada. Estudos experimentais em laboratório mostram que a remoção da polpa dentária produz alterações em regiões específicas do sistema nuclear trigeminal, mais precisamente no núcleo interpolar. Essas alterações são verdadeiras "cicatrizes" que representam as mudanças neurais decorrentes da manipulação periférica. O estímulo irritante, através da dor, deixa cicatrizes invisíveis. Neuropeptídeos como a substância $\mathrm{P}$ como aminoácidos excitatórios (glutamato) estão envolvidos nos mecanismos da neuroplasticidade. Ativam os neurônios de segunda ordem que despolarizam intensamente e aumentam a excitabilidade dos neurônios nociceptivos. Em decorrência, há ativação dos receptores NMDA, que são considerados importantes no aparecimento e manutenção da sensibilização central 
(hiperalgesia secundária e alodínia). Esta por sua vez, por gerar fenômenos como da desinibição, que contribuem para susceptibilização à dor, e decorrem de processos inflamatórios crônicos (Sessle, 2005).

Efeitos excitatórios centrais: a seqüência de eventos acima descrita propicia a resposta ampla do organismo perante estímulos dolorosos. Seja na dor aguda ou na dor crônica, esses eventos ativam o sistema nervoso neurovegetativo responsável por parte dessas manifestações, da mesma forma que ativa o sistema motor (p.ex.: músculo-esquelético mandibular). A perfuração por broca da dentina não anestesiada, ao provocar dor, gera resposta imediata pelo doente, como: palidez, taquicardia e fuga. Doentes com dores crônicas no segmento facial podem ter dor muscular secundária, a exemplo de algumas disfunções temporomandibulares, independente das condições oclusais que apresentem. Neste aspecto, o controle da dor póscirúrgica em implantodontia é fundamental para a prevenção de todos esses fatores, que muitas vezes são mal compreendidos na prática clínica. Salientese que as alterações emocionais que se seguem ao estímulo nocivo, e fazem parte da resposta dolorosa, jamais deveriam ser subestimadas. Seu reconhecimento pelo clínico demonstra seu domínio nos mecanismos de dor e facilita o controle desta (Sessle, 2005).

Além disso, estudos recentes mostram que inflamação e infecção de tecidos periféricos, incluindo a região orofacial, induzem alterações imunológicas no SNC que contribuem para a cronicidade da dor e aparecimento de fenômeno de sensibilização central com produção de 
citocinas inflamatórias que contribuem para a hiperalgesia (Watkins, Maier, 2000; Xie et al., 2007).

$\mathrm{Na}$ dor por nocicepção, especialmente a aguda, a modulação é realizada por diversas substâncias: bradicinina, acetilcolina, prostaglandina, histamina, serotonina, leucotrieno, tromboxano, fator de ativação plaquetária, radicais ácidos, íons potássio, substância $P$, neurocinina $A$ e $B, C G R P$ e óxido nítrico (NO) (Anbar, Gratt, 1997) e contribuem para sensibilização, periférica e central, e para a neuroplasticidade (Lamote, 1992). Na dor crônica ocorrem alterações no sistema nervoso central, como sensibilização central, neuroplasticidade, disfunção do sistema descendente inibitório e alterações emocionais (Ren, Dubner, 2002) e os doentes parecem ter mais susceptibilidade à dor músculo-esquelética facial quando apresentam dores freqüentes no corpo (John et al., 2003; Camparis, Siqueira, 2006). Sabe-se também que inflamação e infecção periféricas causam sensibilização do sistema nervoso central (Xie et al., 2007, Staud, 2007).

\subsubsection{Epidemiologia das dores orofaciais}

Levantamento sobre as dores mais freqüentes na população brasileira indicou que lombalgia (65,9\%), dor de cabeça tensional $(60,2 \%)$, dores musculares $(50,1 \%)$, enxaqueca $(48,6 \%)$, dor de estômago $(43,2 \%)$, dor nas costas $(41,2 \%)$ e dor de dente $(38,4 \%)$ constituíam-se as principais queixas (Teixeira, 1994). Estes dados confirmam, também entre os brasileiros, que o segmento cefálico é um dos locais de maior prevalência de dor, fato que é 
realçado pela importância das estruturas aí alojadas e pela multiplicidade de especialistas dedicados às diversas sub-especialidades que se dedicam a esse segmento do corpo.

A prevalência da dor crônica nas comunidades varia de 7 a $40 \%$ (Andersen, Worm-Perdensen, 1987). No Brasil, mais de $1 / 3$ da população julga que a dor crônica compromete as atividades habituais e mais de 3/4 consideram que a dor crônica limita as atividades recreacionais, relações sociais e familiares (Teixeira et al., 1999). Dores orofaciais nos últimos seis meses que precederam a investigação ocorreram em cerca de $22 \%$ da população consultada (Lipton et al., 1993). Dores de dente (odontalgias) têm múltiplas origens e ocorrem em cerca de $12 \%$ dos adolescentes brasileiros em área urbana, sendo que $8 \%$ deles relatam afastamento das atividades diárias, na família ou na escola (Góes, 2001).

No Brasil, as odontalgias e as cefaléias são queixas de 38 e $60 \%$ respectivamente da população investigada, sendo que as cefaléias são de múltiplas origens, incluindo a região orofacial (Teixeira et al., 1999). Estudo sobre dor orofacial persistente mostrou que cerca de $22 \%$ deles apresentavam dor dental, pulpar ou periodontal, difusa na região crânio-facial (Siqueira et al., 2004).

\subsubsection{Classificação das dores orofaciais}

Existem diversas classificações de dor, entre elas destaca-se a Classificação Internacional de Cefaléias e Dores Crânio-faciais (The 
International Classification of Headache Disorders, 2004), que considera em seu item 11 as cefaléias secundárias ou dor facial associada a distúrbio de crânio, pescoço, olhos, ouvidos, nariz, seios, dentes, boca ou a outras estruturas da face ou crânio, e no seu item 13 trata das neuralgias cranianas e causas centrais de dor facial.

Recentemente, a Academia Americana de Dor Orofacial publicou nova edição do seu Guidelines for Assessment, Diagnosis, and Management (AAOP, 2008), onde complementa a classificação de cefaléias e sugere critérios para o diagnóstico diferencial de subgrupos específicos de dores orofaciais.

Portanto, quanto à origem, há multiplicidade de fontes potenciais de dores orofaciais, podendo-se genericamente classificá-las do seguinte modo: alvéolo-dentárias, musculoesqueléticas, neuropáticas, neurovasculares, psiquiátricas / psicológicas ou referidas de áreas adjacentes da cabeça e pescoço ou de outras regiões do corpo (Okeson, 2006; AAOP, 2008).

\subsubsection{Disfunção Temporomandibular (DTM)}

Pelo Guidelines for Assessment, Diagnosis, and Management (AAOP, 2008), disfunções temporomandibulares são anormalidades musculoesqueléticas do aparelho mastigatório que podem causam dores, agudas ou crônicas, normalmente recorrentes, e associadas a impacto leve ou moderado na atividade social do doente. Portanto, quando presente, a dor pode ser muscular, articular ou mista (Von Korff, 1995). A dor da própria ATM 
é decorrente de várias anormalidades ou doenças; pode ser aguda ou crônica e não obrigatoriamente progressiva (de Leeuw et al., 1994). A dor muscular tem origem nos músculos mastigatórios e pode envolver as cadeias musculares adjacentes da região cervical. Portanto, a denominação DTM engloba condições dolorosas, normalmente crônicas, decorrentes de músculos mastigatórios, ATM e estruturas associadas (McNeill, 1993).

A etiologia das DTM é multifatorial, englobando fatores locais e sistêmicos, como oclusão dentária, bruxismo, sexo, traumatismos, doenças sistêmicas, genéticos, etc (AAOP, 2008; Scrivani et al., 2008). O sexo feminino aumenta o risco para a dor musculoesquelética mandibular, a exemplo de outras dores crônicas, como cefaléias primárias, lombalgias e fibromialgia. É possível que o uso de estrógenos no período da menopausa aumente o risco de DTM (LeResche et al., 1994). Entre outros vários fatores envolvidos encontram-se os: comportamentais, hormonais, morfológicos e emocionais (Unruh, 1996). Considera-se que a idade de pico é aos 45 anos, com variações que dependem do subgrupo de anormalidade envolvido. Em geral há redução da dor por DTM nas idades mais avançadas (Von Korff et al., 1988).

A localização da dor primária por DTM freqüentemente é o ouvido, a região pré-auricular, a face, o ângulo da mandíbula, a órbita, a têmpora e a nuca. A dor pode ser unilateral ou bilateral e pode haver história de dor migratória envolvendo ora o lado direito, ora o lado esquerdo da face. A 
manutenção da dor pode sensibilizar o sistema nervoso central e causar alterações musculares secundárias, do que resulta ampliação da área de representação da dor para o crânio e região cervical (Siqueira, 2001).

A despeito dos inúmeros testes que avaliam os ruídos da ATM ou a atividade da musculatura mandibular, o diagnóstico das DTM é ainda essencialmente clínico. Devem-se descartar doenças estruturais que provocam sintomatologia similar, como os tumores do complexo maxilomandibular ou das áreas adjacentes, como crânio e orofaringe. A limitação de abertura bucal, os desvios mandibulares durante a função, os ruídos articulares e o movimento mandibular doloroso podem ser evidenciados. Anormalidades da oclusão dentária, desgastes dentários de natureza diversa e dor dentária devem ser avaliados no contexto do histórico do doente e não isoladamente. Os músculos sensíveis à palpação, as regiões de endurecimento muscular e a presença de pontos dolorosos desencadeantes de dor são elementos relevantes para o diagnóstico de dor muscular (Travell, Simon, 1992).

Os mecanismos envolvidos na patogênese dos sinais e sintomas de DTM incluem (Stohler, 1999): (1) sensibilização periférica dos tecidos; (2) neuroplasticidade nos circuitos pró-nociceptivos e anti-nociceptivos e (3) sensibilização comportamental, associada com alterações emocionais e com a responsividade autonômica e neuroendócrina específica da dor. Estes 
mecanismos podem explicar a grande variabilidade de apresentação clínica das DTM.

\subsubsection{Dores neuropáticas orofaciais}

A dor neuropática é a dor iniciada ou causada por lesão primária ou disfunção do sistema nervoso (IASP, 1994). Ela é de difícil tratamento e pode ser periférica ou central, sendo que a cavidade oral pode ser afetada em decorrência de traumatismos externos ou cirúrgicos ou secundária a doenças locais ou sistêmicas que afetem a cavidade oral, como é o caso do DM (Okeson, 1996; The International Classification of Headache Disorders, 2004)

Segundo Collin et al. (2000), a ND constitui fator de risco para a DTM uma vez que a perda da sensibilidade pode induzir deformidades e alterações articulares. Por outro lado, a hiperestesia ou disestesia pode limitar a manutenção da higiene oral diária, o que levaria à maior prevalência de cárie e doença periodontal.

Em neuropatias periféricas ocorrem sensibilizações das sinapses das unidades nociceptivas centrais e aumento do número de receptores e das dimensões dos botões sinápticos das fibras nervosas remanescentes, expansão do campo receptivo e melhor eficácia das conexões sinápticas dos aferentes das regiões vizinhas àquela afetada, proliferação das terminações axonais e aumento na distribuição espacial das terminações dos aferentes intactos nos locais afetados devido ao mecanismo de brotamento (Kennedy et 
al., 1999). Além disso, hipoatividade das vias inibitórias pré-sinápticas segmentares, alteração no padrão da organização da chegada dos potenciais de ação ao corno posterior da medula espinal (CPME), aumento do número de potenciais ectópicos, degeneração das projeções centrais dos aferentes primários, modificação da quantidade de neurotransmissores liberados pelas terminações nervosas proximais, perda das conexões sinápticas normais, modificação do padrão morfológico celular, aumento do volume dos neurônios do CPME, modificações anatômicas e funcionais nas células de origem dos tratos rostrocaudais na medula espinal e nas vias caudorrostrais e nos neurônios das unidades do tronco encefálico e tálamo participam na fisiopatologia da dor neuropática (Teixeira, 2001).

\subsection{SÍNDROME DA ARDÊNCIA BUCAL (SAB)}

A Associação Internacional para o Estudo da Dor (Merskey, Bogduk, 1994) define a síndrome da ardência bucal (SAB) como dor em queimação na língua ou em outra mucosa oral. Já a Classificação Internacional de Cefaléias e Dores Crânio-faciais (The International Classification of Headache Disorders, 2004), no seu item 13, classifica a SAB como dor facial de causa central. Portanto, a SAB é considerada uma afecção intra-oral dolorosa, onde geralmente não há sinais de doença e caracteriza-se pela sensação de dor e 
queimação na mucosa oral, não relacionada a anormalidades clínicas ou laboratoriais (Bergdahl, Anneroth, 1993, Grushka, 1987).

Vários sinônimos são utilizados para descrever esta síndrome, como: glossopirose, estomatopirose, glossodínia, estomatodínia, língua ardente, queimação bucal e disestesia oral. Porém, o termo síndrome parece mesmo o mais apropriado, uma vez que muitos doentes também relatam outros sintomas associados, como xerostomia subjetiva, alteração de sabor, dor de cabeça, insônia, etc (Zakrzewska, 2002). Sede, dor na articulação temporomandibular, dor ou sensibilidade nos músculos da mastigação, do pescoço, dos ombros e dos suprahioídeos também podem acompanhar a sensação de ardor (Gorsky et al., 1991). Irritabilidade, mudanças nos hábitos alimentares, depressão e diminuição da sociabilidade também acompanham os sintomas locais (Maltsman-Tseikhin et al., 2007).

\subsubsection{Classificação da SAB}

Como os conceitos de SAB mostram-se insuficientes para estabelecer critérios adequados para o seu diagnóstico e tratamento, atualmente existe a tendência de agrupar os doentes com queixa de ardor bucal em dois grupos (Scala et al., 2003):

a) ardência primária, essencial ou idiopática, quando não se encontram razões clínicas ou laboratoriais que justifiquem a queixa de queimor 
b) ardência secundária, onde os sintomas são resultado de alguma doença local ou sistêmica, como aftas, odontalgias, infecções, DM, fibromialgia e anemia, entre outras.

Estudo em nosso meio, sobre doentes com queixas de queimação na cavidade oral, mostrou que cerca da metade apresentavam doenças crônicas ou condições sistêmicas que poderiam originar neuropatias periféricas, e entre eles $7 \%$ relatavam ter DM (Nasri et al., 2007). Outro estudo também realizado em nosso meio mostrou que o câncer oral também deve ser incluído no diagnóstico diferencial da queimação oral, pois em cerca de $3.5 \%$, de 271 doentes a ardência bucal foi o motivo inicial da procura por assistência à saúde (Cuffari et al., 2006).

\subsubsection{Ardor bucal e neuropatia diabética}

Apesar da etiologia da SAB ainda ser desconhecida, fortes indícios na literatura recente sugerem que a SAB seja uma dor neuropática. Grushka, Sessle (1991) observaram mudanças no paladar e/ou disfunções sensitivas/químicas sugerindo uma origem neuropática para esta síndrome. Distúrbios na percepção de estímulos térmicos (Svensson et al., 1993); alterações na transmissão neuronal e aumento na sensibilidade trigeminal (Gao et al., 2000); polineuropatia subclínica envolvendo perda funcional das fibras nervosas de pequeno diâmetro (Lauritano et al., 1998); mudanças morfológicas difusas nas fibras nervosas do epitélio e subepitélio, compatíveis com degeneração axonal (Lauria et al., 2005) e redução do número de fibras 
nervosas. Maltsman-Tseikhin et al. (2007) e Yilmaz et al. (2007) sugerem que a SAB pode estar associada à neuropatia sensitiva de pequenas fibras trigeminais.

Outras neuropatias faciais, como a neuralgia do trigêmeo e a neuralgia pós-herpética, comprometem a sensibilidade orofacial, envolvendo, inclusive os ramos trigeminais ipsolaterais não afetados (Siqueira et al., 2006; 2007; Kurogi et al., 2007). Também em doentes com ardência bucal foram encontradas alterações no nervo corda do tímpano (Eliev et al., 2007).

Curiosamente, as neuropatias estão entre as complicações mais comuns do DM, afetando até $50 \%$ dos doentes diabéticos e são classificadas em neuropatia sensitiva aguda, que é precipitada por instabilidade glicêmica, e neuropatia sensitiva motora crônica, que é a forma mais comum de neuropatia periférica (Boulton, 2005).

Até o presente momento não existem estudos que quantifiquem a sensibilidade do território trigeminal em doentes diabéticos, e muito menos naqueles que já apresentam diagnóstico de neuropatia diabética em outras regiões do corpo, fato que indica necessidade de novos estudos nessa área. 


\subsection{OBJETIVOS}

Neste estudo foram avaliados doentes com diagnóstico de Diabetes mellitus tipo 2, com os seguintes objetivos:

a) avaliar as características gerais da amostra;

b) determinar a prevalência de dores orofaciais e de queixas de ardência bucal;

c) avaliar a condição de saúde bucal;

d) avaliar a prevalência de dor e disfunção mandibular;

e) avaliar os aspectos emocionais e de impacto da dor nos doentes com Diabetes mellitus tipo 2.

f) avaliação quantitativa da sensibilidade dolorosa no território de inervação trigeminal; 


\subsection{CASUÍSTICA E MÉTODOS}

Dentre 62 doentes com diagnóstico de Diabetes mellitus avaliados no Centro de Dor do Hospital das Clínicas da Faculdade de Medicina da Universidade de São Paulo, no período de janeiro/2007 a janeiro/2008, 29 preencheram os critérios de inclusão para este estudo e foram encaminhados ao ambulatório da Equipe de Dor Orofacial da Divisão de Odontologia do Hospital das Clínicas da Faculdade de Medicina da Universidade de São Paulo (EDOF-HCFMUSP). Os doentes selecionados tinham idade entre 37 a 77 anos (média de 57,86 anos), 17 eram do sexo feminino (58,6\%) e 12 do sexo masculino $(41,4 \%)$.

O estudo foi aprovado pela CAPPesq - Comissão de Ética do Hospital das Clínicas da Faculdade de Medicina da Universidade de São Paulo [Anexo 1] e o termo de consentimento livre e esclarecido foi informado e assinado por todos os doentes da pesquisa [Anexo 2]

Desenho do estudo: transversal exploratório Instrumentos de avaliação:

Os doentes serão submetidos a anamnese e exame físico detalhados, utilizando-se os seguintes instrumentos diagnósticos:

1) Ficha clínica da Divisão de Odontologia da EDOF-HCFMUSP: protocolo de avaliação clínica em dores orofaciais, incluindo as características gerais de dor orofacial: tipo de queixa, duração, localização, freqüência, 
intensidade, fator inicial, tratamentos realizados, tipo de dor, fatores de melhora e de piora, presença cefaléia e de dores generalizadas no corpo e morbidades associadas (Siqueira, Teixeira, 2001) [Anexo 3];

2) Research Diagnostic Criteria for Temporomandibular Disorders (RDC/TMD): questionário para uso em pesquisa, traduzido para o português e adaptado culturalmente (Pereira et al., 2004; Kosminsky et al., 2004)[Anexo 4];

3) Questionário McGill para avaliação de dor, validado na língua portuguesa (Pimenta, Teixeira, 1996) [Anexo 5];

4) Ficha de Exame Periodontal [Anexo 6];

A avaliação periodontal constou dos seguintes índices: Índice de Sangramento (IS) à sondagem; Profundidade Clínica de Sondagem (PCS) e Profundidade Clínica de Inserção (PCI), para avaliar, através destes parâmetros clínicos o grau de comprometimento periodontal e atividade de doença. A inflamação gengival foi avaliada pelo índice de sangramento gengival, determinado pelo número de superfícies sangrantes após sondagem com sonda periodontal, multiplicado por 100 e dividido pelo número total de superfícies (Ainamo, Bay 1975).

6) Exames sensitivos orofaciais correspondentes à região trigeminal (pele e mucosa oral) (Siqueira et al.,2006) [Anexo 7];

6.1 Sensibilidade dolorosa com algiômetro de agulha (Micromar, Diadema, Brasil)

Para avaliação complementar dos resultados dos testes quantitativos de sensibilidade trigeminal (QST), foi utilizado um grupo controle para comparação. Este grupo controle foi constituído de 24 sujeitos saudáveis (10 
homens e 14 mulheres), sem queixas de dores orofaciais ou morbidades sistêmicas, com média de idade de 40,13 anos, com a mínima de 16 anos e a máxima de 75 anos.

7) Análise estatística: inicialmente todas as variáveis foram analisadas descritivamente. Para as variáveis quantitativas esta análise foi feita através da observação dos valores mínimos e máximos, e do cálculo de médias e desvios-padrão e medianas. Para as variáveis qualitativas, calcularam-se freqüências absolutas e relativas. Para se testar a hipótese de igualdade entre os dois lados foi utilizado o teste não-paramétrico de Wilcoxon e para a comparação entre os grupos o teste não-paramétrico de Mann-Whitney, pois a suposição de normalidade dos dados foi rejeitada. A correlação entre duas variáveis foi analisada através do coeficiente de correlação de Spearman.

O nível de significância utilizado para os testes foi de 5\%.

\section{Critérios de inclusão}

Doentes encaminhados do Centro Multidisciplinar de Dor da Divisão de Neurologia do HC-FMUSP com diagnóstico de Diabetes Mellitus tipo 2 e neuropatia diabética periférica, ainda sem tratamento para esta condição álgica. 


\section{Critérios de exclusão}

Doentes com Diabetes mellitus do tipo 1 e doentes com doenças

psiquiátricas graves, sem condição cognitiva de participar do estudo, gestantes, ou que se recusem a participar do estudo. 


\subsection{RESULTADOS}

\subsection{Características dos doentes com Diabetes mellitus tipo 2}

A glicemia média em jejum da amostra foi de $166 \mathrm{mg} / \mathrm{dL}$ e a taxa média de hemoglobina glicada $\left(\mathrm{HbA}_{1 \mathrm{c}}\right)$ foi de 9,17\% (Tabela 1)

Tabela 1 - Distribuição dos doentes avaliados segundo o controle glicêmico e o tempo de tratamento do DM $(n=29)$.

\begin{tabular}{ccccc}
\hline & $\mathrm{N}$ & Média $( \pm \mathrm{dp})$ & Mediana & Variação \\
\hline $\begin{array}{c}\text { Glicemia em jejum } \\
(\mathrm{mg} / \mathrm{dL})\end{array}$ & 27 & $\begin{array}{c}163,67 \\
( \pm 74,16)\end{array}$ & 150 & $77-335$ \\
$\begin{array}{c}\text { Hemoglobina glicada } \\
(\%)\end{array}$ & 27 & 9,17 & & \\
$\begin{array}{c}\text { Índice de massa } \\
\text { corpórea (IMC) }\end{array}$ & 25 & $\begin{array}{c}29,4 \\
( \pm 2,13)\end{array}$ & $29,90,1-14,6$ & $18,4-46,4$ \\
$\begin{array}{c}\text { Tempo de tratamento } \\
\text { do DM (em anos) }\end{array}$ & 27 & 9,74 & & $1-30$ \\
\hline
\end{tabular}

Os membros inferiores, especialmente os pés e a região da panturrilha, foram os locais de maior prevalência de neuropatia diabética, sejam avaliados isolados ou associadamente a outras regiões acometidas com a condição álgica (Tabela 2). 
Tabela 2 - Localização das queixas de neuropatia diabética dos doentes com $\operatorname{DM}(n=29)$.

\begin{tabular}{ccc}
\hline Local da neuropatia & N & $\%$ \\
\hline MMII* $^{*}$ & 14 & 48,2 \\
MMII e MMSS $^{* *}$ & 6 & 20,6 \\
MMII e Tronco & 4 & 13,7 \\
Tronco & 3 & 10,3 \\
MMSS & 1 & 3,4 \\
MMSS e Tronco & 1 & 3,4 \\
\hline Total & 29 & 100,0 \\
\hline${ }^{*}$ - membros inferiores; ${ }^{* *}$ - membros superiores & &
\end{tabular}

Todos os doentes do grupo estudado apresentavam outra doença concomitante, além do DM, sendo que a mais predominante foi a hipertensão arterial sistêmica (HAS). A Tabela 3 mostra a distribuição dessas doenças. O número total de morbidades associadas foi maior que o da amostra avaliada, pois grande parte dos doentes apresentava mais que duas alterações sistêmicas concomitantes.

Tabela 3 - Morbidades associadas encontradas nos doentes com DM ( $\mathrm{n}=$ 29).

\begin{tabular}{lc}
\hline Morbidades associadas & $\mathrm{N}(\%)$ \\
\hline Hipertensão arterial sistêmica (HAS) & $15(51,7 \%)$ \\
Gastrite & $10(34,4 \%)$ \\
Alterações sistema cardiovascular & $7(24,1 \%)$ \\
Alterações sistema respiratório & $6(20,6 \%)$ \\
Alterações renais & $5(17,2 \%)$ \\
Depressão & $3(10,3 \%)$ \\
Câncer & $3(10,3 \%)$ \\
Hipotireoidismo & $2(6,8 \%)$ \\
\hline
\end{tabular}




\subsection{Características odontológicas}

$\mathrm{Na}$ amostra avaliada, 16 doentes $(55,2 \%)$ eram parcialmente dentados, sendo que $6(20,6 \%)$ apresentaram doença periodontal leve/moderada; 4 $(13,7 \%)$ doença periodontal avançada e $6(20,6 \%)$ doença periodontal avançada localizada; 13 doentes $(44,8 \%)$ eram totalmente desdentados.

O índice médio de sangramento gengival na amostra foi de $18,94 \%$.

\subsection{Prevalência e características das dores orofaciais}

Queixa de dor orofacial estava presente em 16 casos $(55,2 \%)$, sendo que em 5 (representam $17,2 \%$ da amostra total) a dor era em queimor, ardência ou formigamento na região orofacial. $O$ valor médio $( \pm d p)$ da Escala Visual Analógica $(E V A)$ foi de $5,6( \pm 3,53)$. Dois doentes $(6,8 \%)$ referiram ranger os dentes à noite. Observe os dados relativos às queixas de dores em diferentes regiões do corpo, incluindo o segmento cefálico, e relato de bruxismo do sono conforme informação de parceiro de quarto, na Tabela 4. 
Tabela 4 - Prevalência de dores e de auto-relatos de bruxismo do sono nos doentes com DM obtidos através da ficha EDOF-HC $(n=29)$

\begin{tabular}{lcccl}
\hline & Sim & Não & Não sabe & Total \\
\hline Dor orofacial & $16(55,2 \%)$ & $13(44,8 \%)$ & 0 & $29(100 \%)$ \\
Ardor bucal & $5(17,2 \%)$ & $24(82,8 \%)$ & 0 & $29(100 \%)$ \\
Dor de cabeça & $16(55,2 \%)$ & $13(44,8 \%)$ & 0 & $29(100 \%)$ \\
Dor de ouvido & $7(24,2 \%)$ & $22(75,8 \%)$ & 0 & $29(100 \%)$ \\
Dor no corpo & $29(100 \%)$ & 0 & 0 & $29(100 \%)$ \\
Dor matinal no rosto & $7(24,2 \%)$ & $22(75,8 \%)$ & 0 & $29(100 \%)$ \\
Dor matinal no corpo & $23(79,3 \%)$ & $6(20,6 \%)$ & 0 & $29(100 \%)$ \\
Ranger dos dentes & $2(6,8 \%)$ & $22(75,8)$ & $5(17,2 \%)$ & $29(100 \%)$ \\
\hline
\end{tabular}

$\mathrm{Na}$ avaliação da dor através do questionário McGill, oito doentes (50\%) relataram os descritores latejante, pontada e agulhada, e nove doentes $(56 \%)$ relataram calor, queimação formigamento ou ardor. Os descritores mais freqüentes foram: latejante em seis doentes $(37,5 \%)$ e pontada em quatro (25\%). Dos descritores afetivos, cansativa em oito doentes $(50 \%)$ foi a mais freqüente. Veja na Tabela 5 os resultados do questionário McGill.

Tabela 5 - Número de descritores e índice de dor de acordo com o questionário McGill de avaliação de dor

\begin{tabular}{lcc}
\hline & $\begin{array}{c}\text { Média do número de } \\
\text { descritores } \mathrm{n}(\%)\end{array}$ & $\begin{array}{c}\text { Média dos índices de } \\
\text { dor } \mathrm{n}(\%)\end{array}$ \\
\hline Sensitivos & $4(51,2 \%)$ & $8(66,6 \%)$ \\
Afetivos & $1,5(19,2 \%)$ & $1,8(15 \%)$ \\
Avaliativos & $0,7(8,9 \%)$ & $1,2(10 \%)$ \\
Miscelânea & $1,4(17,9 \%)$ & $2,7(22,5 \%)$ \\
Total & $7,8(100 \%)$ & $12(100 \%)$ \\
\hline
\end{tabular}


Em relação à intensidade da dor, seis $(37,5 \%)$ doentes apresentaram dor de intensidade forte, cinco $(31,25 \%)$ de intensidade moderada e cinco $(31,25 \%)$ com intensidade fraca (Tabela 6$)$.

Tabela 6 - Características da dor orofacial nos doentes com DM (ficha clínica EDOF-HC).

\begin{tabular}{ccccc}
\hline \multirow{2}{*}{ Freqüência } & \multicolumn{3}{c}{ Intensidade da dor } & \multirow{2}{*}{ Total } \\
\cline { 2 - 4 } & $\begin{array}{c}\text { Fraca } \\
\mathrm{n}(\%)\end{array}$ & $\begin{array}{c}\text { Moderada } \\
\mathrm{n}(\%)\end{array}$ & $\begin{array}{c}\text { Forte } \\
\mathrm{n}(\%)\end{array}$ & $\mathrm{n}(\%)$ \\
\hline Contínua & 0 & $1(6,25)$ & $1(6,25)$ & $2(12,5)$ \\
Intermitente & $5(31,25)$ & $4(25)$ & $5(31,25)$ & $14(87,5)$ \\
Total & $5(31,25)$ & $5(31,25)$ & $6(37,5)$ & $16(100)$ \\
\hline
\end{tabular}

Nos 16 doentes com queixa de dor orofacial, nove $(56,2 \%)$ relataram a mastigação, nervosismo, deglutição, frio e calor como fatores de piora da dor. Os fatores de melhora relatados por oito $(50 \%)$ dos doentes foram: uso de analgésicos, pressão local, medicação para o DM, ingestão de açúcar, líquidos gelados. 


\subsection{Avaliação da prevalência de dor e disfunção mandibular (RDC/TMD}

\section{Eixo 1)}

Quanto às disfunções musculares, nove doentes (31\%) apresentaram dor miofascial e 20 (69\%) não receberam qualquer outro diagnóstico deste grupo de disfunções (Tabela 7).

Tabela 7 - Distribuição dos doentes quanto ao diagnóstico de dor muscular mastigatória de acordo com o questionário RDC/TMD Eixo 1

\begin{tabular}{cccc}
\hline Dor miofascial & $\begin{array}{c}\text { Dor miofascial com } \\
\text { limitação de abertura bucal }\end{array}$ & $\begin{array}{c}\text { Ausência de } \\
\text { sintomas }\end{array}$ & Total \\
\hline $\mathrm{n}(\%)$ & $\mathrm{n}(\%)$ & $\mathrm{n}(\%)$ & $\mathrm{n}(\%)$ \\
$9(31)$ & 0 & $20(69 \%)$ & $29(100 \%)$ \\
\hline
\end{tabular}

Quanto ao deslocamento do disco articular, na ATM direita, um doente $(3,4 \%)$ apresentou diagnóstico de deslocamento com redução, três $(10,3 \%)$ apresentaram diagnóstico de deslocamento de disco sem redução e sem limitação de abertura bucal e 25 (86,2\%) não apresentaram alterações; na ATM esquerda, três doentes (10,3\%) apresentaram deslocamento sem redução e com limitação da abertura bucal e $26(89,7 \%)$ não apresentaram alterações. Não há outros diagnósticos em qualquer dos lados.

Dos 29 doentes, dois $(6,9 \%)$ apresentaram artralgia do lado D e dois $(6,9 \%)$ do lado esquerdo; $27(93,1 \%)$ não tinham alterações do lado direito nem do esquerdo (Tabela 8). 
Tabela 8 - Diagnóstico de anormalidades da articulação temporomandibular (ATM) de acordo com o questionário RDC/TMD Eixo 1

\begin{tabular}{lcc}
\hline Variável & ATM D n (\%) & ATM E n (\%) \\
\hline Desloc. c/ redução & $1(3,4)$ & 0 \\
Desloc. s/ redução, s/ Lim. abertura bucal & $3(10,3)$ & 0 \\
Desloc. s/ redução, c/ Lim. abertura bucal & 0 & $3(10,3)$ \\
Artralgia & $2(6,9)$ & $2(6,9)$ \\
Osteoartrite & 0 & 0 \\
Osteoartrose & 0 & 0
\end{tabular}

Desloc=deslocamento, Lim=limitação, c/=com, s/=sem

As características referentes à mobilidade mandibular podem ser observadas na Tabela 9. Dois doentes não tiveram valores levados em consideração por serem desdentados totais e não utilizarem próteses dentárias, o que inviabilizou a aferição das medidas.

Tabela 9 - Características da mobilidade mandibular (RDC/TMD Eixo 1) nos doentes com DM ( $n=29)$.

\begin{tabular}{lcccc}
\hline & $\mathrm{N}$ & Média $( \pm \mathrm{dp})$ & Mediana & Variação \\
\hline Abertura bucal máxima $(\mathrm{mm})$ & 27 & $45,21( \pm 13,75)$ & 46 & $0-63$ \\
Lateralidade D $(\mathrm{mm})$ & 27 & $8,55( \pm 2,65)$ & 8 & $0-14$ \\
Lateralidade E $(\mathrm{mm})$ & 27 & $8,34( \pm 2,74)$ & 8 & $0-14$ \\
Protrusão $(\mathrm{mm})$ & 27 & $6,75( \pm 2,09)$ & 7 & $0-10$ \\
\hline
\end{tabular}


A função mandibular foi normal em 26 (89,7\%) dos doentes avaliados, três doentes $(10,3 \%)$ apresentaram grau de limitação moderada da função mandibular (Figura 1).

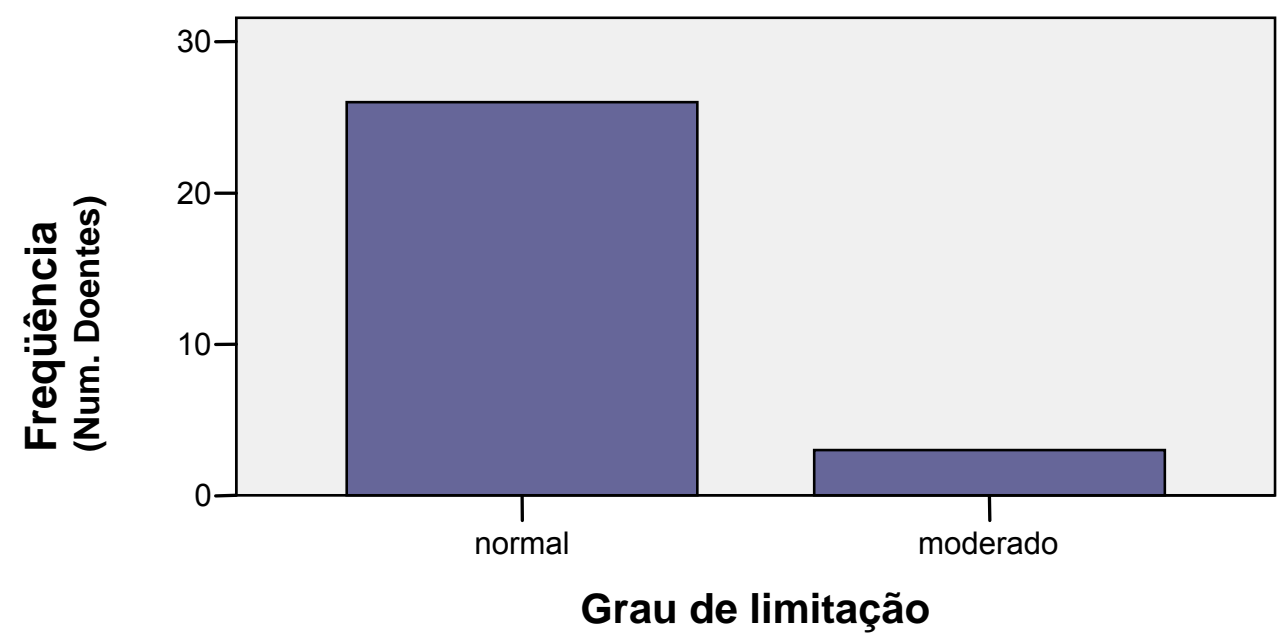

Figura 1 - Distribuição dos doentes segundo a limitação da função mandibular (RDC/TMD Eixo 1) 


\subsection{Avaliação emocional e de incapacidade por dor (RDC/TMD Eixo 2)}

Observamos que $10(34,5 \%)$ dos doentes apresentaram algum tipo de incapacidade baixa, seja ela com baixo nível de dor ou com dor alta; a incapacidade moderada foi observada em um doente $(3,4 \%)$.

A figura 2 mostra o grau de dor crônica observado nos doentes.

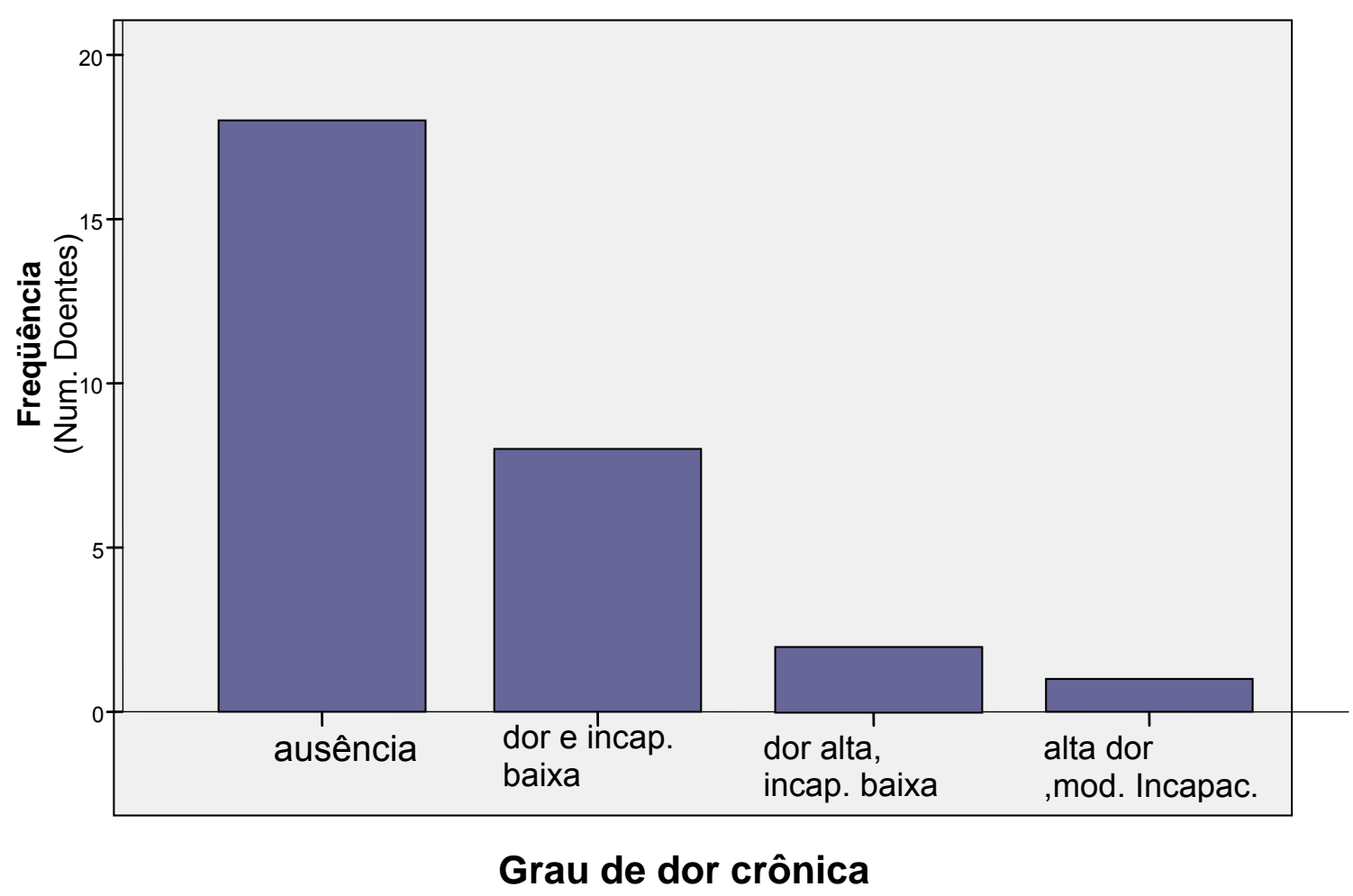

Figura 2 - Distribuição dos doentes segundo o grau de dor crônica e incapacidade (RDC/TMD Eixo 2) 
$\mathrm{Na}$ amostra avaliada, oito doentes $(27,6 \%)$ apresentaram traços depressão moderada e sete deles $(24,1 \%)$ apresentaram traços de depressão grave (Figura 3).

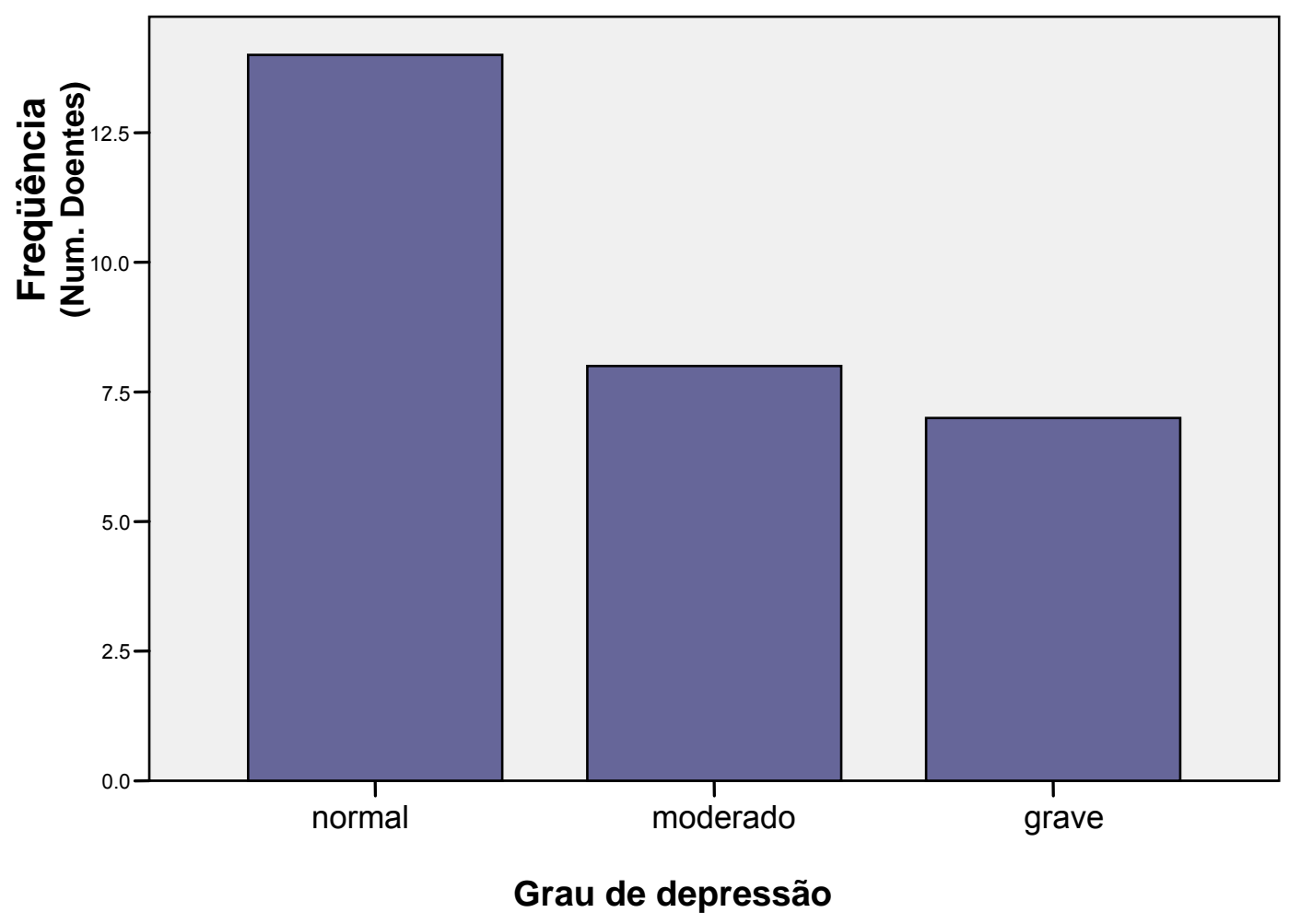

Figura 3 - Distribuição dos doentes segundo a presença de traços de depressão (RDC/TMD Eixo 2) 
Em relação aos sintomas físicos inespecíficos, nove doentes (31\%) tiveram traços moderados e seis doentes $(20,7 \%)$ traços graves (Figura 4$)$.

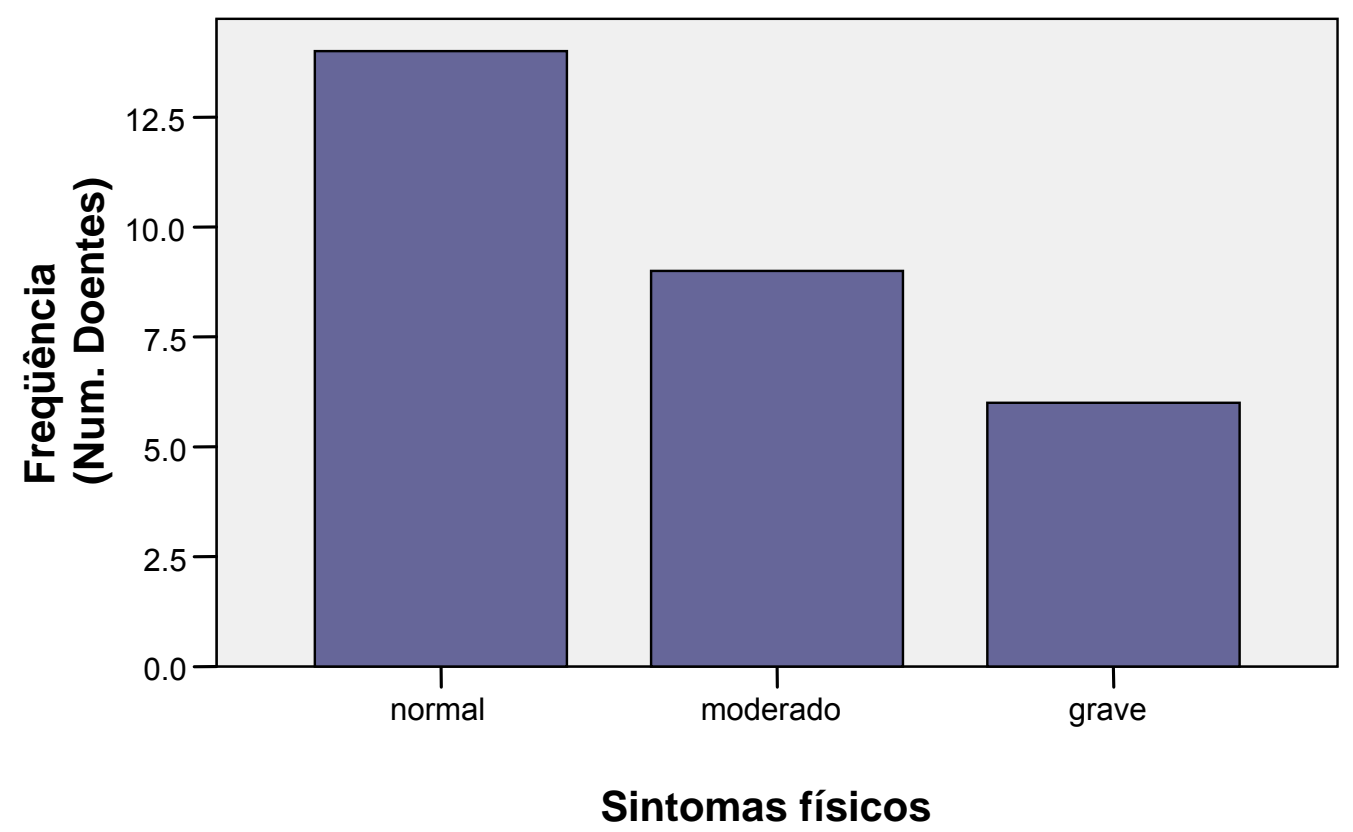

Figura 4 - Distribuição dos doentes quanto a presença de sintomas físicos inespecíficos (RDC/TMD Eixo 2)

\subsection{Avaliação da sensibilidade trigeminal}

A avaliação algiométrica do nervo trigêmeo nos doentes com DM foi realizada comparativamente entre doentes com e sem dores orofaciais; entretanto não houve diferença estatisticamente significativa entre eles (Tabela 10). 
Tabela 10 - Comparação das algiometrias do $\vee$ par craniano entre os doentes com DM, respectivamente com e sem dor orofacial $(n=29)$.

\begin{tabular}{ccccccccc}
\hline \multicolumn{1}{c}{ Variável } & $\begin{array}{c}\text { Dor } \\
\text { orofacial }^{n}\end{array}$ & Média & $\mathrm{dp}$ & Mínimo & Máximo & Mediana & $\mathrm{p}^{*}$ \\
\hline Algiometria V1D & Sim & 16 & 49,25 & 33,10 & 12 & 100 & 35 & 0,092 \\
& Não & 13 & 24,08 & 7,15 & 10 & 36 & 26 & \\
Algiometria V1E & Sim & 16 & 40,63 & 27,84 & 10 & 100 & 38 & 0,200 \\
& Não & 13 & 27,69 & 23,05 & 14 & 100 & 20 & \\
Algiometria V2D & Sim & 16 & 34,75 & 23,21 & 12 & 100 & 28 & 0,423 \\
& Não & 13 & 27,00 & 11,80 & 14 & 52 & 22 & \\
Algiometria V2E & Sim & 16 & 32,00 & 23,49 & 10 & 100 & 26 & 0,232 \\
& Não & 13 & 20,69 & 12,82 & 10 & 58 & 17 & \\
Algiometria V3D & Sim & 16 & 34,38 & 20,35 & 10 & 80 & 26 & 0,589 \\
& Não & 13 & 29,08 & 17,62 & 10 & 70 & 25 & \\
Algiometria V3E & Sim & 16 & 34,63 & 23,91 & 10 & 100 & 28 & 0,329 \\
& Não & 13 & 24,85 & 10,82 & 10 & 42 & 24 & \\
\hline
\end{tabular}

$\left({ }^{*}\right)$ nível descritivo de probabilidade do teste não-paramétrico de MannWhitney.

$\mathrm{Na}$ avaliação dos doentes com DM houve diferença estatisticamente significativa no valor da algiometria de V2 lado direito em comparação com o lado oposto $(p=0,017)$ (Tabela 11). 
Tabela 11 - Algiometria do território trigeminal dos doentes com DM $(n=29)$.

\begin{tabular}{cccccccc}
\hline Variável & $\mathrm{n}$ & Média & $\mathrm{dp}$ & Mínimo & Máximo & Mediana & $\mathrm{p}^{*}$ \\
\hline Algiometria V1 lado D & 29 & 37,97 & 27,77 & 10 & 100 & 28 & 0,229 \\
Algiometria V1 lado E & 29 & 34,83 & 26,19 & 10 & 100 & 24 & \\
& & & & & & & \\
Algiometria V2 lado D & 29 & 31,28 & 19,07 & 12 & 100 & 24 & 0,017 \\
Algiometria V2 lado E & 29 & 26,93 & 19,97 & 10 & 100 & 20 & \\
& & & & & & & \\
Algiometria V3 lado D & 29 & 32,00 & 19,03 & 10 & 80 & 25 & 0,746 \\
Algiometria V3 lado E & 29 & 30,24 & 19,51 & 10 & 100 & 26 & \\
\hline
\end{tabular}

$\left({ }^{*}\right)$ nível descritivo de probabilidade do teste não-paramétrico de Wilcoxon

$\mathrm{Na}$ correlação entre a algiometria com a glicemia e $\mathrm{HbA}_{1 c}$, a correlação foi positiva em relação à algiometria de $\mathrm{V} 2$ direito e $\mathrm{V} 3$ esquerdo e a $\mathrm{HbA}_{1 c}$ (Tabela 12).

Tabela 12 - Correlação entre glicemia, $\mathrm{HbA}_{1 c}$ e algiometria dos doentes com DM.

\begin{tabular}{cccccccc}
\hline & & algioV1D & algioV1E & algioV2D & algioV2E & algioV3D & algioV3E \\
\hline Glicemia & $\mathrm{r}$ & 0,359 & 0,313 & 0,206 & 0,142 & 0,119 & 0,139 \\
& $\mathrm{p}$ & 0,066 & 0,112 & 0,302 & 0,479 & 0,553 & 0,490 \\
$\mathrm{HbA}_{1 \mathrm{c}}$ & $\mathrm{r}$ & 0,365 & 0,334 & 0,383 & 0,271 & 0,250 & 0,440 \\
& $\mathrm{p}$ & 0,067 & 0,095 & 0,054 & 0,181 & 0,218 & 0,024 \\
\hline
\end{tabular}

(r) coeficiente de correlação e Spearman

Na correlação entre as algiometrias de V1, V2 e V3 do grupo de estudo houve correlação significativa tanto do lado $D$ quanto $E$, mostrando que o aumento no valor de um dos ramos implica no aumento do valor dos outros ramos (Tabela 13). 
Tabela 13 - Correlação entre as algiometrias de V1, V2 e V3 dos doentes com DM.

\begin{tabular}{|c|c|c|c|c|c|c|c|}
\hline & & V2 D & V3 D & & & V2 E & V3 E \\
\hline \multirow[t]{3}{*}{ V1 D } & $r$ & 0,611 & 0,426 & V1 E & $r$ & 0,698 & 0,763 \\
\hline & $p$ & $<0,001$ & 0,021 & & $p$ & $<0,001$ & $<0,001$ \\
\hline & $\mathrm{n}$ & 29 & 29 & & $n$ & 29 & 29 \\
\hline \multirow[t]{3}{*}{ V2 D } & $r$ & & 0,521 & V2 E & $r$ & & 0,678 \\
\hline & $p$ & & 0,004 & & $p$ & & $<0,001$ \\
\hline & $\mathrm{n}$ & & 29 & & $\mathrm{n}$ & & 29 \\
\hline
\end{tabular}


4.7 Avaliação de sensibilidade trigeminal, comparativamente entre os doentes com DM (estudo) e o grupo controle

Na comparação entre grupo de doentes com DM e o grupo de sujeitos saudáveis também houve diferença estatisticamente significativa $(p=0,007)$ (Figura 5).

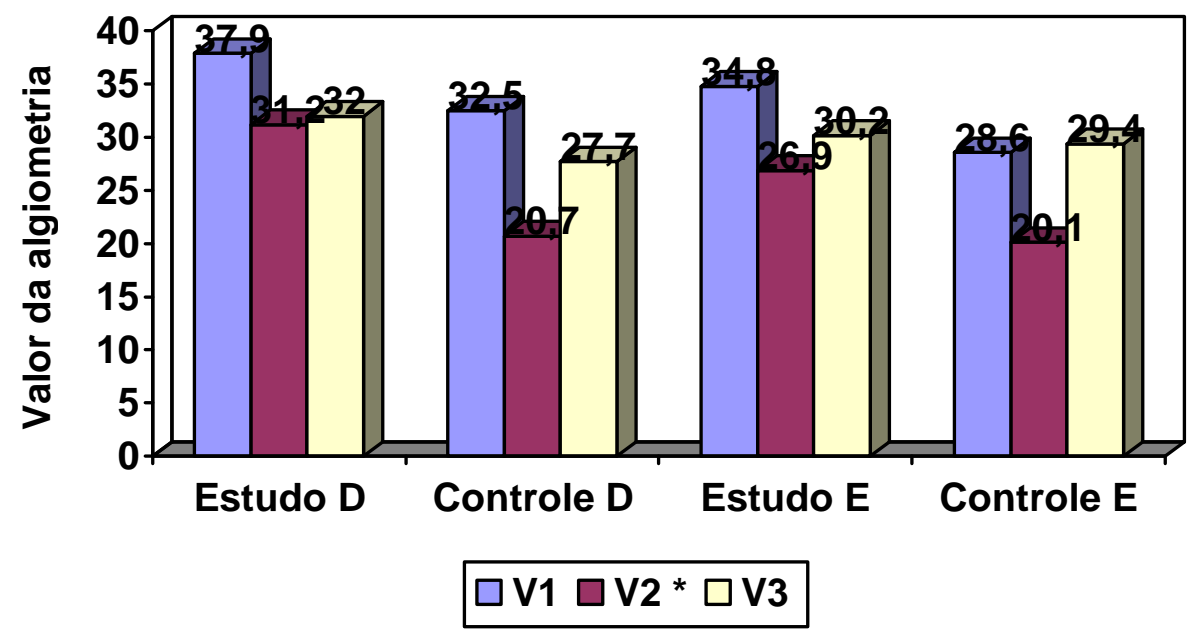

${ }^{*} \mathrm{p}=0,007$ - comparativamente ao V2 D do grupo de estudo.

Figura 5 - Avaliação da algiometria trigeminal comparativamente entre o grupo de estudo (DM) e o controle. 
A Figura 6 mostra a comparação entre a algiometria de V2 lado direito, entre os grupos de estudo e controle.

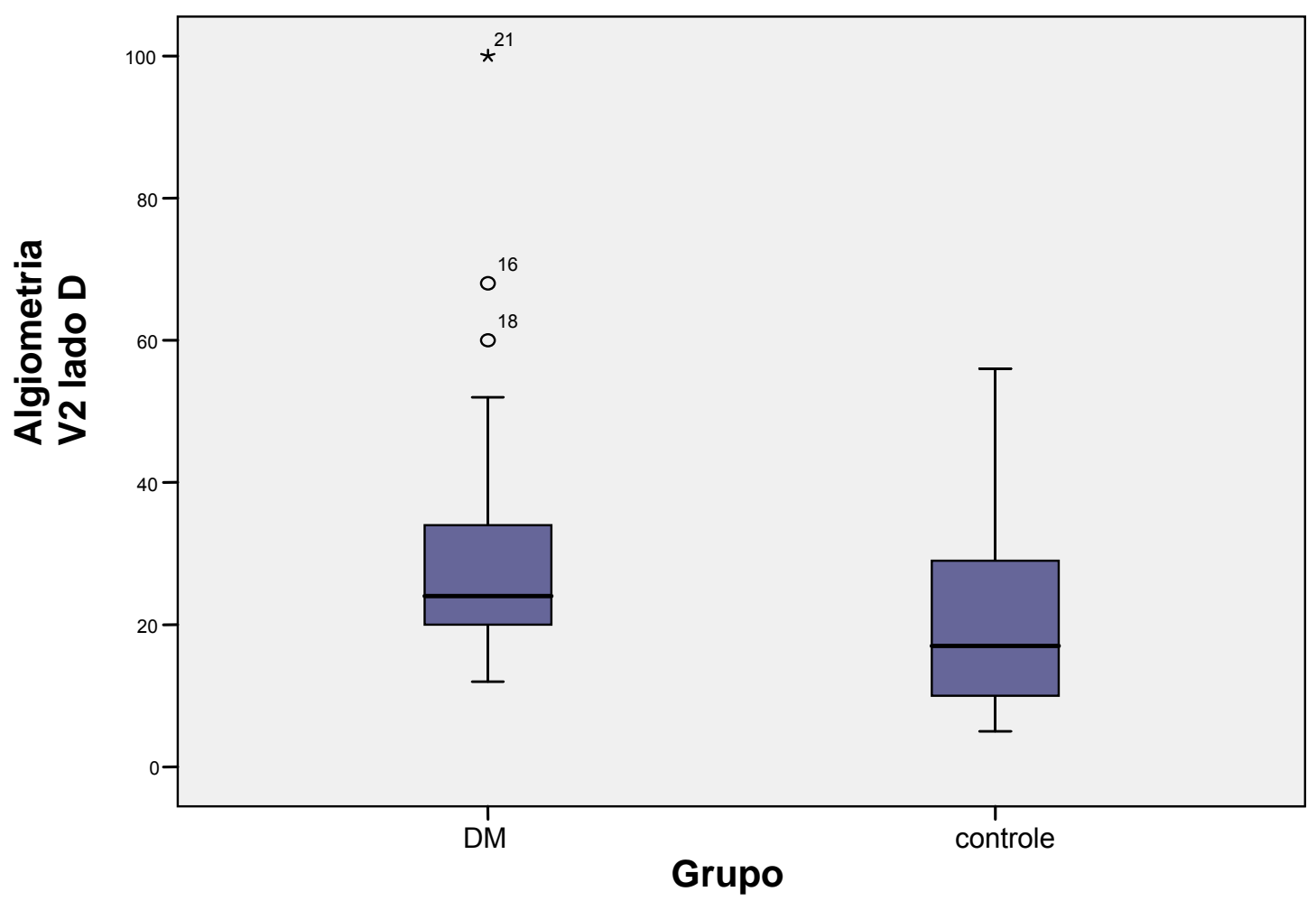

Figura 6 - Box plot para comparação entre a algiometria de V2 lado direito entre os grupos de estudo e controle 


\subsection{DISCUSSÃO}

Apesar das alterações orais serem consideradas como uma das possíveis complicações do DM, o conhecimento da relação entre essa doença e a sensibilidade do território trigeminal ainda é escasso, particularmente nos doentes que já apresentam diagnóstico de neuropatia diabética, como é o caso desta amostra. Dos doentes avaliados, todos se queixaram de dor atribuída à neuropatia diabética, sendo que destes, em 37,9\% a localização foi nas regiões mais distais do corpo e de forma simétrica, dado que é compatível com a literatura científica (Boulton, 2005).

Sabe-se que maiores tempos de duração da doença e a falta de controle glicêmico aceleram as complicações tardias do DM, tais como retinopatia, vasculopatia, nefropatia e neuropatia (White et al., 2003; Manfredi et al., 2004). Na amostra estudada a média de glicemia dos doentes foi de $166 \mathrm{mg} / \mathrm{dL}$ e a taxa de $\mathrm{HbA}_{1 \mathrm{c}}$ média foi de $9,17 \%$. Portanto, esses valores estão acima dos considerados normais, ou seja, até $100 \mathrm{mg} / \mathrm{dL}$ para a glicemia e 4\% a 7\% para $\mathrm{HbA}_{1 \mathrm{c}}$ (White et al., 2003; ADA, 2007). A média de idade foi de 56 anos, e o tempo médio de tratamento do DM foi de 9.7 anos. Portanto, são doentes sujeitos à ocorrência de neuropatia diabética pelo DM, pois a ocorrência dessa complicação relaciona-se à duração do DM, ao controle metabólico e à idade do doente, embora não exista relação obrigatória entre sua ocorrência e presença de complicações como micro e macroangiopatia (Teixeira, Silva, 2006). A dor também não é ocorrência 
obrigatória, mesmo nas neuropatias sensitivas (Spruce et al., 2003) Porém, nesta amostra todos os doentes procuraram atendimento devido à dor.

Mais da metade dos doentes apresentou hipertensão arterial sistêmica como morbidade associada, condição que pode ser decorrente tanto da idade média da amostra, pois geralmente ela acomete indivíduos mais idosos, como também devido a complicações da própria doença. Já a presença levemente superior do sexo feminino $(58,6 \%)$ foi compatível com a própria prevalência do DM na população geral (Adeghate et al., 2006).

Saúde oral e o DM

O DM é considerado fator de risco para doenças periodontais e estas, por sua vez, podem comprometer o controle do DM (Mealey et al., 2003; Manfredi et al., 2004). Como doenças infecciosas crônicas, as doenças periodontais trazem riscos sistêmicos (Mealey, Rose, 2008), o que exige avaliação freqüente da cavidade oral, principalmente quando existem doenças sistêmicas crônicas, como o DM, que sofre influência de infecções. As doenças periodontais também aumentam o risco de aterosclerose e de doenças cardiovasculares, que é um risco também do DM (Costa et al., 2004; Marques et al., 2007). Curiosamente, cerca de 55\% dos doentes deste estudo apresentaram doença periodontal, sendo que em $20.6 \%$ ela foi considerada avançada, o que aumenta os riscos sistêmicos (Manfredi et al., 2004; Mealey, Rose, 2008). Estes são relevantes, pois a doença periodontal é freqüente na população geral (Projeto SB Brasil, 2003); ainda não existe uma consciência de sua morbidade e de que sendo doença infecciosa deveria ser sempre 
pesquisada em doentes de risco e devidamente tratada (Mealey, Rose, 2008). Neste contexto, este continua sendo um relevante dado deste estudo. Os doentes foram encaminhados para tratamento odontológico.

Sobre as queixas de dores orofaciais

Além de todos os doentes apresentarem dor no corpo, pois foi o critério de inclusão do próprio estudo, mais da metade deles também referiu dor no segmento cefálico: cabeça, face e ouvido. Não foi objetivo deste estudo, portanto não foram especificadas essas questões, entretanto o valor médio das dores orofaciais foi de 5.6 (EVA), variando de leve a forte pela informação verbal (Tabela 4). Enquanto os valores do questionário McGill para os descritores dessas dores mostraram enorme variação em todas as modalidades avaliadas. Não se pode descartar a presença de sensibilização central decorrente do conjunto dessas dores, já que pode ocorrer somação temporal em tais casos, principalmente quando há dor generalizada no corpo (Staud et al., 2007). A presença de dor matinal no corpo ou na face pode também indicar alterações do sono, o que é comum em doentes crônicos, mas que não foi motivo desta investigação. Esses dados indicam que os doentes desta amostra apresentam dor crônica não restrita a uma única região, embora este estudo esteja avaliando a região orofacial. Deste modo, como veremos adiante, as alterações comportamentais e a própria incapacitação pela dor crônica são frequentemente mais acentuadas.

Prevalência de dor e disfunção mandibular (RDC/TMD Eixo 1) 
Outro dado importante neste estudo mostrou que cerca de $30 \%$ dos doentes apresentou dor miofascial mastigatória durante a avaliação clínica. Dor miofascial é uma condição álgica muito comum, que pode ocorrer primária ou secundariamente a várias síndromes álgicas, e tem origem multifatorial, incluindo fatores locais e sistêmicos. Alem disso, sabe-se que a ND é um fator de risco para DTM (Collin et al., 2000). Além de causar dor facial, pode causar dores secundárias de cabeça e no pescoço (Watkins, Maier, 2000; Xie et al., 2007). Curiosamente, o ardor ou queimação na região orofacial pode ser um sintoma dessa condição crônica. $O$ fato de que muitos doentes referiram cansaço facial ao acordar pode decorrer do comprometimento muscular e aumentar o desconforto na região. Porém, também pode decorrer, como discutimos acima, da sensibilização central.

Como a mobilidade mandibular desta amostra mostrou valores compatíveis com a população geral, e, portanto, de normalidade, é possível que a última afirmação seja a mais provável, todavia, como muitos doentes apresentaram doença periodontal, e esta pode também ser fator de risco para dor miofascial mastigatória, por ser inflamação crônica periférica que pode causar sensibilização central (Staud et al., 2007). Assim, verificamos que vários fatores de risco estão envolvidos nesta amostra, locais e sistêmicos. Avaliação emocional e do impacto da dor (RDC/TMD Eixo 2)

Outro dado interessante observado neste estudo transversal foi a presença de traços de depressão moderada a grave. Esse dado é compatível com a literatura científica que mostra relação entre dor crônica, como neste 
caso de dor por neuropatia diabética, e alterações emocionais e ou psiquiátricas (Maltsman-Tseikhin et al., 2007; Yilmaz et al., 2007). Ainda que três doentes tenham relatado diagnóstico médico de depressão, é necessário ressaltar que neste estudo os doentes não passaram por avaliação psiquiátrica, e não é possível confirmar a presença ou não de doença psiquiátrica primária ou se as alterações encontradas são conseqüências da presença da dor crônica.

Outro dado freqüente em doentes com dores crônicas é presença de sintomas físicos inespecíficos, o qual também ocorreu em 9 (31\%) e 6 $(20,7 \%)$ doentes com DM, que apresentaram níveis moderados a graves respectivamente dessa condição.

Quanto ao impacto da dor nos doentes, ainda que a maioria não apresentasse alteração, parte deles relatou baixa incapacidade e três $(10,3 \%)$ relataram dor alta e moderada incapacidade. Certamente, esses dados realçam o significado da dor para esses doentes, mas é possível que a característica de cronicidade de sua doença primária, o DM, e a presença da dor pela neuropatia diabética tenham contribuído para esses resultados.

As avaliações comportamental e sobre o impacto da dor (RDC/TMD Eixo 2) realizadas neste estudo são sugeridas para dores orofaciais musculoesqueléticas, o que certamente não foi exclusivo nesta amostra, pois dor é fenômeno complexo e multidimensional, podendo ocorrer somação espacial e temporal e sensibilização central que levam a alterações neuroplásticas e influenciam atividades emocionais, cognitivas e 
neurovegetativas (Sessle, 2005). Como vimos anteriormente este é um grupo de doentes com doença crônica e também com dores crônicas, envolvendo vários fatores que possivelmente contribuíram para esses resultados.

A sensibilidade trigeminal (QST)

Pela literatura consultada, este é o primeiro estudo que avalia quantitativamente a sensibilidade trigeminal em doentes com DM. Sabe-se que, dentre os nervos cranianos, o motor ocular comum, o abducente, e o troclear são os mais freqüentemente afetados, em seguida vem o trigêmeo, o facial e o estato-acústico, sendo que nos casos de neuropatias motoras oculares, as dores ocorrem devem-se aos ramos oftálmico e maxilar do trigêmeo (Teixeira, Silva, 2006). Não ficou estabelecida nesta amostra qual a característica de neuropatia diabética dos doentes que a possuíam.

O dado relevante deste estudo foi a alteração de sensibilidade dolorosa no ramo V2 do lado direito, comparativamente ao lado oposto da face e também aos ramos ipsilateral $(p=0,017)$. Esta alteração teve correlação positiva com os valores de $\mathrm{Hb}$ glicada, respectivamente no $\mathrm{V} 2$ lado direito $(p=0,054)$ e $V 3$ lado esquerdo $(p=0.024)$. Os dados vigentes na literatura referem-se somente a algiometria intra-oral, onde não foi encontrada alteração de sensibilidade pelo DM (Shinkai et al., 2004).

Os dados deste estudo mostram que nem todos os ramos do nervo trigêmeo estão afetados, o que indica que as complicações do DM não afetam de forma homogênea a região, mas de forma irregular, como a literatura já mostra para outras regiões do corpo (Teixeira, Silva, 2006). Em outras áreas 
do corpo, embora a neuropatia diabética seja bilateral na fase crônica, isso nem sempre ocorre nas fases iniciais, e também parece depender do controle adequado da glicemia (Boulton, 2005). Essa pode ser uma possível explicação para esse achado no território trigeminal. No presente estudo observa-se que tanto a taxa de hemoglobina, como de hemoglobina glicada são superiores aos valores normais, o que denota maior dificuldade de controle do DM ou maior gravidade da doença. Como esta é uma amostra de doentes crônicos que freqüentam um hospital terciário, é possível que eles representem um grupo de maior complexidade. Além disso, o fato de já apresentarem dor por neuropatia diabética em outras regiões do corpo pode ser indicativo desse fato.

Curiosamente observamos que houve correlação entre os valores da hemoglobina glicada e da algiometria, que também reforça a possibilidade de comprometimento parcial de ramos terminais do ramo maxilar. Foi utilizado um grupo controle de doentes saudáveis com o objetivo único de comprovar se havia diferença estatística significativa em relação ao V2, o que ficou realmente comprovado, reforçando esse resultado.

Ardência bucal e neuropatia diabética

As queixas de ardência bucal encontradas nesta amostra merecem atenção especial, pois a literatura científica de longa data coloca o DM como causa possível de ardência bucal (Scala et al., 2003; Nasri et al., 2007). Entretanto, como já discutimos anteriormente, até a presente data inexistem estudos quantitativos de sensibilidade no território trigeminal que relacionem 
essas queixas como já decorrentes do DM e, portanto, como sendo já de neuropatia diabética na cavidade oral.

Estudos recentes em doentes com queixa de ardência oral mostraram que cerca de $50 \%$ desses doentes têm alguma doença sistêmica associada, incluindo o DM, como causa primária (Scala et al., 2003; Nasri et al., 2007). Portanto, essas doenças são importantes para o diagnóstico diferencial da síndrome da ardência bucal $(S A B)$, que é considerada primariamente idiopática. No presente estudo $17,2 \%$ dos doentes queixaram-se de ardência bucal, embora, como já discutimos anteriormente, foram encontradas várias doenças locais e sistêmicas que podem causar esse sintoma. Não podemos afirmar que seja decorrente exclusivamente do DM, embora as alterações dolorosas parciais do nervo trigêmeo indiquem também essa possibilidade.

Entre as doenças que podem causar ardência bucal são citadas as doenças gastrointestinais, como a gastrite, a depressão e o hipotireoidismo, que ocorreram respectivamente em 10, 3 e 2 doentes da presente amostra. Portanto, a presença destas condições dificulta mais ainda a avaliação da origem da ardência bucal nesta amostra, podendo inclusive ser multifatorial. Estes dados são relevantes e somam-se às informações da literatura científica sobre esse tema, indicando sua complexidade e necessidade de investigação cuidadosa pelos clínicos, médicos ou dentistas.

Considerações finais e perspectivas

Estes dados em conjunto mostram a complexidade de avaliar estes doentes e de que é difícil estabelecer uma relação causa-e-efeito para 
explicar a dor orofacial, as queixas de ardor bucal ou as suas queixas de cefaléia. Entretanto, as alterações de sensibilidade dolorosa trigeminal evidenciam que já há comprometimento neural periférico, possivelmente relacionado às alterações do $\mathrm{DM}$, e que podem ser sinais precoces de neuropatia diabética trigeminal. Como este foi um estudo transversal exploratório e tem suas limitações, novos estudos longitudinais, prospectivos, certamente são necessários para confirmar estes dados preliminares sobre a sensibilidade dolorosa trigeminal. Entretanto este é uma observação inédita e provavelmente apresentada pela primeira vez na literatura especializada. 


\subsection{CONCLUSÂO}

Pela metodologia utilizada neste estudo podemos concluir:

a) Os níveis de glicemia em jejum e de $\mathrm{HbA}_{1 c}$ apresentaram-se acima dos valores normais. De acordo com o IMC a amostra avaliada teve classificação nutricional de pré obesidade;

b) A prevalência de dores orofaciais foi $55,2 \%$ e de ardor bucal foi $17,2 \%$, sendo que a dor matinal foi queixa freqüente na amostra avaliada;

c) A prevalência de doença periodontal foi $54,9 \%$, sendo que doença periodontal avançada foi encontrada em $41,2 \%$;

d) A prevalência de dor miofascial mastigatória foi 31\%

e) A prevalência de traços de depressão moderada e grave foi $51,7 \%$, a prevalência de sintomas físicos inespecíficos moderados e graves foi $51,7 \%$ e a prevalência de incapacidade baixa e moderada foi $37,9 \%$;

f) Observou-se comprometimento estatisticamente significante da sensibilidade dolorosa (hipoalgesia) em V2 lado D. Houve correlação positiva nas algiometrias de $\mathrm{V} 1, \mathrm{~V} 2$ e $\mathrm{V} 3$ em ambos os lados e correlação positiva das hipoalgesias de $\mathrm{V} 2$ lado $\mathrm{D}$ e $\mathrm{V} 3$ lado $\mathrm{E}$ com os níveis de $\mathrm{HbA}_{1 \mathrm{c}}$. 


\section{ANEXOS}

\section{ANEXO 1}

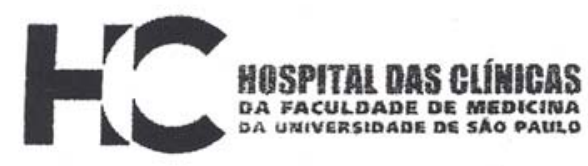

\section{APROVACÃO}

A Comissão de Ética para Análise de Projetos de Pesquisa - CAPPesq da Diretoria Clínica do Hospital das Clínicas e da Faculdade de Medicina da Universidade de São Paulo, em sessão de 27.10.05, APROVOU o Protocolo de Pesquisa $n^{\circ}$ 964/05, intitulado: "Características odontológicas e prevalência da ardência bucal em pacientes com diabetes Mellitus do tipo 2" apresentado pelo Departamento de NEUROLOGIA, inclusive o Termo de Consentimento Livre e Esclarecido.

$$
\text { Cabe ao pesquisador elaborar e apresentar à }
$$

CAPPesq, os relatórios parciais e final sobre a pesquișa (Resolução do Conselho Nacional de Saúde $n^{\circ} 196$, de 10.10.1996, inciso IX. 2, letra "c")

Pesquisador(a) Responsável: Prof. Dr. Manoel Jacobsen Teixeira

Prof. Dr. José Tadeu Tesseroli de Siqueira Pesquisador (a) Executante: Dra. Astrid Arap Elito

CAPPesq, 27 de Outubro de 2005.

$$
\text { Whals cofillo }
$$

PROF. DR. EUCLIDES AYRES DE CASTILHO Presidente da Comissão de Ética para Análise de Projetos de Pesquisa 
ANEXO 2

TERMO DE CONSENTIMENTO LIVRE E ESCLARECIDO

\section{I - DADOS DE IDENTIFICAÇÃO DO SUJEITO DA PESQUISA OU RESPONSÁVEL LEGAL}

1. NOME DO PACIENTE :

DOCUMENTO DE IDENTIDADE $\mathrm{N}^{\circ}:$ SEXO : $M \quad F$ DATA NASCIMENTO:

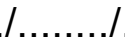
ENDEREÇO

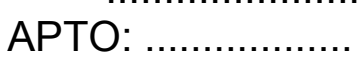

BAIRRO:

TELEFONE:

DDD

CIDADE:

CEP:

2.RESPONSÁVEL \begin{tabular}{ccc} 
& \multicolumn{2}{c}{ LEGAL } \\
parentesco, & tutor, & curador
\end{tabular} NATUREZA (grau de parentesco, DOCUMENTO DE IDENTIDADE : DATA NASCIMENTO: ENDEREÇO: $\mathrm{N}^{\circ}$ SEXO: $M \quad F$ BAIRRO: APTO:

CEP: TELEFONE: DDD (

CIDADE:

II - DADOS SOBRE A PESQUISA CIENTÍFICA

1. TÍTULO DO PROTOCOLO DE PESQUISA

Características odontológicas e prevalência da ardência bucal em pacientes com Diabetes Mellitus tipo 2.

PESQUISADOR: Astrid Arap CARGO/FUNÇÃO: Pós graduanda INSCRIÇÃO CONSELHO REGIONAL DE ODONTOLOGIA № 77293 UNIDADE DO HCFMUSP: Divisão de Odontologia/ ICHC 
2. AVALIAÇÃO DO RISCO DA PESQUISA:

MÉDIO

SEM RISCO RISCO MÍNIMO $\mathbf{X}$

RISCO

RISCO BAIXO

RISCO MAIOR

(probabilidade de que o indivíduo sofra algum dano como consequência imediata ou tardia do estudo)

3.DURAÇÃO DA PESQUISA : 12 meses

\section{III - REGISTRO DAS EXPLICAÇÕES DO PESQUISADOR AO PACIENTE OU SEU REPRESENTANTE LEGAL SOBRE A PESQUISA CONSIGNANDO:}

1. justificativa e os objetivos da pesquisa: $\operatorname{Sr}(a)$, os pacientes que têm Diabetes Mellitus, como é o seu caso, apresentam, freqüentemente, complicações nos maxilares e nos dentes, como dor e infecções, e necessitam de orientação e tratamento odontológico. Este estudo tem o objetivo de avaliar os problemas mais comuns na boca e na face, de tal forma que se consiga melhor orientação e tratamento, quando necessário. Assim, é possível contribuir para o tratamento dessas dores.

2. procedimentos que serão utilizados e propósitos, incluindo a identificação dos procedimentos que são experimentais: Serão realizados os exames e tratamentos comuns em Odontologia, como o exame da boca, dos músculos da face e das articulações da mandíbula, além de moldagem das arcadas dentárias. Serão feitas também radiografias dos dentes e dos maxilares; exames que já fazem parte da rotina para avaliação odontológica dos pacientes aqui no hospital. Todos esses procedimentos não são testes novos ou desnecessários, são bem conhecidos e indispensáveis para conhecer os problemas odontológicos.

3. desconfortos e riscos esperados: Os riscos dos exames odontológicos ou das radiografias são mínimos e são os habituais desses procedimentos, ou seja: radiação pelos exames radiográficos, um pouco de irritação nas gengivas devido ao exame e um pouco de cansaço no maxilar por permanecer com a boca aberta.

4. benefícios que poderão ser obtidos: $A$ identificação de problemas na boca ou nos maxilares pode contribuir para o seu tratamento e melhora. 
5. procedimentos alternativos que possam ser vantajosos para o indivíduo

\section{IV - ESCLARECIMENTOS DADOS PELO PESQUISADOR SOBRE GARANTIAS DO SUJEITO DA PESQUISA CONSIGNANDO:}

1. acesso, a qualquer tempo, às informações sobre procedimentos, riscos e benefícios relacionados à pesquisa, inclusive para dirimir eventuais dúvidas.

2. liberdade de retirar seu consentimento a qualquer momento e de deixar de participar do estudo, sem que isto traga prejuízo à continuidade da assistência.

3. salvaguarda da confidencialidade, sigilo e privacidade.

4. disponibilidade de assistência no HCFMUSP, por eventuais danos à saúde, decorrentes da pesquisa.

5. viabilidade de indenização por eventuais danos à saúde decorrentes da pesquisa.

Você não receberá nenhuma compensação financeira pela participação na pesquisa.

\section{INFORMAÇÕES DE NOMES, ENDEREÇOS E TELEFONES DOS RESPONSÁVEIS PELO ACOMPANHAMENTO DA PESQUISA, PARA CONTATO EM CASO DE INTERCORRÊNCIAS CLÍNICAS E REAÇÕES ADVERSAS.}

Dra. Astrid Arap / Dr. José Tadeu T. de Siqueira

Equipe de Dor Orofacial da Divisão de Odontologia do HC-FMUSP

Tel: 3069-6393 


\section{OBSERVAÇÕES COMPLEMENTARES:}

\section{VII - CONSENTIMENTO PÓS-ESCLARECIDO}

Declaro que, após convenientemente esclarecido pelo pesquisador e ter entendido o que me foi explicado, consinto em participar do presente Protocolo de Pesquisa.

São Paulo, de de 200 .

assinatura do sujeito da pesquisa ou responsável legal

assinatura

do pesquisador

(carimbo

ou nome legível) 


\section{ANEXO 3}

Ficha Clínica da Equipe de Dor Orofacial / ATM

Divisão de Odontologia do Hospital das Clínicas - FMUSP

Dentista:

Data:

Procedência

Nome: Sexo:

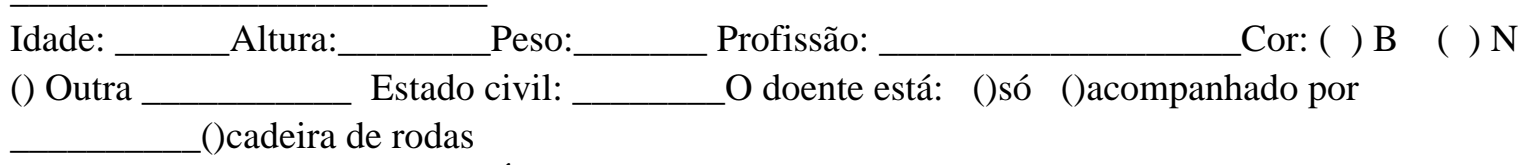

I. ANAMNESE - CARACTERÍSTICAS DA DOR

$1-\mathrm{QP}(\mathbf{Q u a l}$ é a sua

queixa?)

2.- Há quanto tempo você tem essa dor?:

()Dias ()Meses ()Anos ․‥ Periodicidade:

()Diária... ()2-3 X sem ()Sem ()Quinz ()Mensal.

4. Periodo do dia que tem dor: ()M ()T ()N ()Indiferente $\quad \underline{5}$ : Como ela aparece?

()Espontanea: ()N ()S; . ()Provocada: ()N ()S- Como?

6 Quanto

tempo dura a sua dor? ()segs ()mins ()horas ()dias ()Outro

7. Tipo (caracteristica) da dor: ()Pontada ()Peso ()Queimor ()Choque ()Latejante () Contínua ()Outro

8 - Intensidade da dor: ( ) fraca ( ) moderada ( ) forte 9.- Nota de 0 a 10 :

$10-$

Essa dor te acorda durante o sono? ()N ()S

11 - Período do dia em que a dor é pior: ()M ()T ()N ()sono ()indiferente

Ooutro:

13. Sabe o que iniciou a sua dor? ()N: () S- Como?

14 - O que piora a sua

dor?

15 - O que acalma a sua

dor?

16 - Tratamentos realizados para a dor e melhora

(M,PM,SM)

17 - Possui o hábito de morder: ( ) língua ( ) bochecha ( ) lábios ( ) objetos:

18 - Você mastiga do lado: ( )D ( )E ( ) na frente ( ) bil (dos 2 lados) 


\section{ANEXO 4 \\ Ficha Clínica da Equipe de Dor Orofacial / ATM e RDC Divisão de Odontologia do Hospital das Clínicas - FMUSP}

Dentista:

Data:

Procedência :

Nome:

Sexo:

Idade:

Altura:

Peso:

Profissão:

Cor: ( ) B ( ) N ()

Outra

Estado civil:

O paciente está: ()só ()acompanhado por

()cadeira de rodas

I. ANAMNESE - CARACTERÍSTICAS DA DOR

1 - QP (Qual é a sua

queixa?)

2.- Há quanto tempo você tem essa dor?:

()Dias ()Meses ()Anos ‥ Periodicidade: ()Diária... ()2-3 X sem ()Sem

()Quinz ()Mensal.

4. Periodo do dia que tem dor: ()M ()T ()N ()Indiferente

5: Como ela aparece? ()Espontanea: ()N ()S; .

()Provocada: ()N ()S- Como?

$\underline{6}$ Quanto tempo dura a sua dor? ()segs ()mins ()horas

()dias ()Outro

7. Tipo (caracteristica) da dor: ()Pontada ()Peso ()Queimor ()Choque ()Latejante () Contínua ()Outro

8 - Intensidade da dor: ( ) fraca ( ) moderada ( ) forte 9.- Nota de 0 a 10 :

10 - Essa dor te acorda

durante o sono? ()N ()S

11 - Período do dia em que a dor é pior: ()M ()T ()N ()sono ()indiferente

()outro:

13. Sabe o que iniciou a sua dor? ()N: () S- Como?

14 - O que piora a sua

dor?

15 - O que acalma a sua

dor?

16 - Tratamentos realizados para a dor e melhora

(M,PM,SM)

17 - Possui o hábito de morder: ( ) língua ( ) bochecha ( ) lábios ( ) objetos: 
18 - Você mastiga do lado: ( )D ( )E ( ) na frente ( ) bil (dos 2 lados)

19 - Você acha que sua mastigação é:

()boa ()ruim ()péssima ()não sabe ()causa dor - Onde?

20 - Ao acordar sente alguma dor em seu corpo? ()N ()S:- ()rosto ()ouvido ()cabeça ()dentes ()pescoço ()corpo ()Outro

21 - Sente o rosto cansado com frequência: ()N ()S - ( ) ao acordar ( ) ao mastigar ( ) ao falar ( ) ao sorrir ( ) outro

22 - Sabe se range os dentes: ()à noite ()de dia ( )não sabe ( )N ( )S: Quem disse?

23 - Sente ruídos na ()face ()cabeça ( )N ()S- Lado? Quando? ( ) AB ( ) fala ( ) mastiga ()outro

24 - Tem dor provocada por algum movimento da boca? ()N ()S - ( ) AB ( ) Protrusão ( ) later. D ( ) Later.E ()outro

25 - Tem dor de ouvido? ( )N ( )S: Lado? ()D ()E Passou pelo médico (ORL)? ()N ()S - O que ele disse?

26 - Tem dor de cabeça? ( )N ( )S: Onde?

27 - Passou pelo médico (Neuro)? ()N ()S - o que ele disse ou receitou?

28 - Tem dor no corpo: ()N ()S: Onde?

29- Passou pelo médico? ()N ()S- Qual?

O que ele disse ou receitou?

30 - Teve algum acidente, cirurgia ou doença grave? ()N ()S - Qual, como e onde afetou seu corpo?

12- Mostre onde é a sua dor.

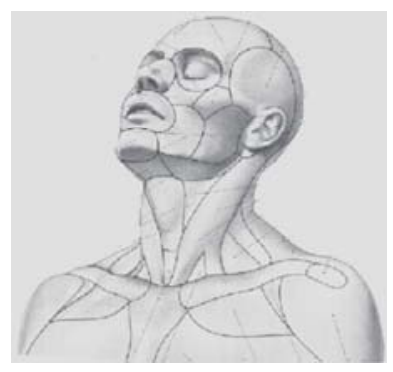

III. ANTECEDENTES MÉDICOS PESSOAIS:

()Artrite reumatóide

()Fibromialgia

()Rinite alérgica

()Enxaqueca

()Herpes zoster (cobreiro)
()D ()E ()Bilateral;

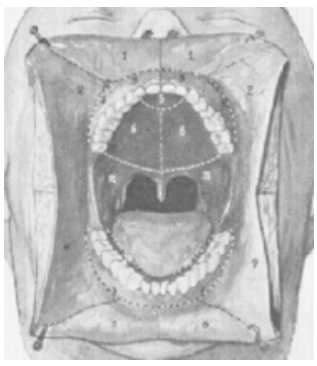

e as dores do seu corpo.

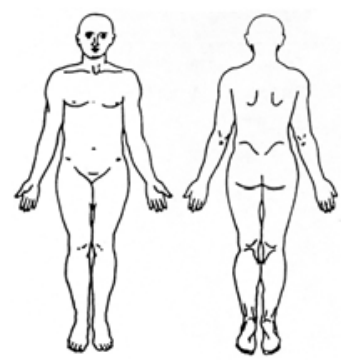

31 - Tratou-se de alguma destas doenças:

\begin{tabular}{|c|c|c|c|c|}
\hline ()Asma & ()Bronquite & ()Hepatite & ()Amigdalite & ()Derrame ( ( )AVC \\
\hline ()Sinusite & & ()Pressão alta (HAS) & ()Diabete & ()Úlcera ()Gastrite \\
\hline ()Coraçã & & ()Doença renal (rins) & ()Depressão & ()Infecções \\
\hline
\end{tabular}

()Outra: 
32 - Está em tratamento médico atual? Doenças que tem e remédios que usa:

IV. ASPECTOS PSICOLÓGICOS

33 - Comportamento durante a consulta:

\section{EXAME FÍSICO:}

34 - Face: ()Assimetria facial ()Prognatismo ( )Laterognatismo:-D E Hipertrofia: ()Masseter ()Temporal - ()D ()E 35 - Pele da Face:

36 - Linfonodos:

37 - Mucosa oral:

38 - Lingua:

39 - Alterações neurológicas:

40 - Periodonto:

41 - Dentes:

42 - Percussão (Vert e Horiz) (0 a 3)

43 - Ausências dentárias (/)

$\begin{array}{llllllllllllllll}18 & 17 & 16 & 15 & 14 & 13 & 12 & 11 & 21 & 22 & 23 & 24 & 25 & 26 & 27 & 28\end{array}$

44 - Interferências oclusais:

$\begin{array}{llllllllllllllll}48 & 47 & 46 & 45 & 44 & 43 & 42 & 41 & 31 & 32 & 33 & 34 & 35 & 36 & 37 & 38\end{array}$

45 - Mordida aberta: ( )S ( )N 46. Mordida cruzada: ( )Ant ( )Post- ()D ()E 47- Sobremordida profunda: ()N ()S - ( )a ( )b ( )c

48 - Desgastes dentários: ()N ()S - ( )incisais ( )1/3 incisal ( )1/3 médio ( )1/3 cervical 49 - Angle:

()CI I ()Cl II () Cl III

50 - Desdentado Total: ()Sup ()Inf ()Duplo 51-PPR: ()N ()S - Qual: 52 -Perda de DV:()N ()S - _ _ mm 53 - Tempo de uso de PT:

; 54 - Tempo da PT atual: 55 Tempo de uso da PPR:

56 - Movimentos mandibulares: AB:ativa $\mathrm{mm}$ passiva - ()sem dor ()com dor - local:

P:___ mm - ()sem dor ()com dor - local: $\mathrm{mm}$ - ()sem dor ()com dor - local: ; LE: $\mathrm{mm}-()$ sem dor ()com dor - local: Linha Media:desvio corrigido ( )S ( )N DLMf: ___ mm ()E ()D DLMa: __ mm - ()E ()D

57 - Ruídos na ATM: ()Ausentes ()POP crepitação fina () grosseira () () D () E Estalo D- ()IA ()MA ()FA ()IF ()MF ()FF

Estalo E -()IA ()MA ()FA ()IF

()MF () FF

Estalido recíproco eliminado na protrusiva ( ) S ( ) N-medida do estalido na abertura $\mathrm{mm}$

fechamento $\mathrm{mm}$

58 - Palpação da ATM e dos músculos da mastigação e do pescoço:

\begin{tabular}{|l|l|l|l|}
\hline ATM ou Músculos & Dir & Esq & Obs. \\
\hline ATM - pólo lateral & & & \\
\hline ATM - pólo posterior & & & \\
\hline Masseter Inferior & & & \\
\hline Masseter Médio & & & \\
\hline Masseter Superior & & & \\
\hline
\end{tabular}




\begin{tabular}{|l|l|l|l|}
\hline Masseter Intra-Oral & & & \\
\hline Temporal Anteriorr & & & \\
\hline Temporal Medio & & & \\
\hline Temporal Posterior & & & \\
\hline Temporal Intra-Oral & & & \\
\hline Digástrico anterior & & & \\
\hline Digástrico posterior & & & \\
\hline ECM superior & & & \\
\hline ECM medio & & & \\
\hline ECM inferior & & & \\
\hline Esplênio cervical & & & \\
\hline Esplênio da cabeça & & & \\
\hline Suboccipitais & & & \\
\hline Trapézio ombro & & & \\
\hline Trapézio pescoço & & & \\
\hline Pterigoideo lateral & & & \\
\hline
\end{tabular}

59. Movimentos cervicais dolorosos? ()N ()S- rotação D ()rotação E ()extensão ()flexão obs.

60 - Rx, exames ou interconsultas solicitadas:

61 - Hipótese Diagnóstica para a dor (CID):

62 - Diagnósticos secundários (CID):

63 - Diagnóstico final (dor)

64 - Tratamento sugerido para a dor:

65 - Reabilitações sugeridas:

VI. TRATAMENTO INICIAL (dor):

Data:

1 retorno - data:

( ) SM ( ) PM ( )S ( ) O ( ) SD

( ) $\mathrm{M}: \_\%$

( ) P ( )I

Tratamento realizado:

$\begin{array}{llllll}\text { ( ) SM ( ) PM ( )S ( ) O ( ) SD } & \text { ( ) M: \% \% } & \text { ( ) P ( )I }\end{array}$

$2^{\circ}$ retorno - data:

( ) SM ( ) PM ( )S ( )O ( ) SD

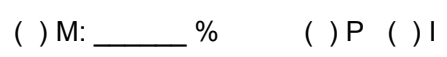

Tratamento realizado:

$3^{\circ}$ retorno - data:

( ) SM ( )PM ( )S ( ) O ( ) SD

( ) M:

$\%$

( ) P ( ) I

Tratamento realizado:

4 retorno - data:

( ) SM ( ) PM ( ) S ( ) O ( ) SD

( ) $\mathrm{M}:$

$\%$

( ) P ( ) I

Tratamento realizado:

$5^{\circ}$ retorno - data:

( ) SM ( )PM ( )S ( ) O ( ) SD

( ) M:

$\%$

( ) P ( ) I

Tratamento realizado:

Obs.: 


\section{RDC}

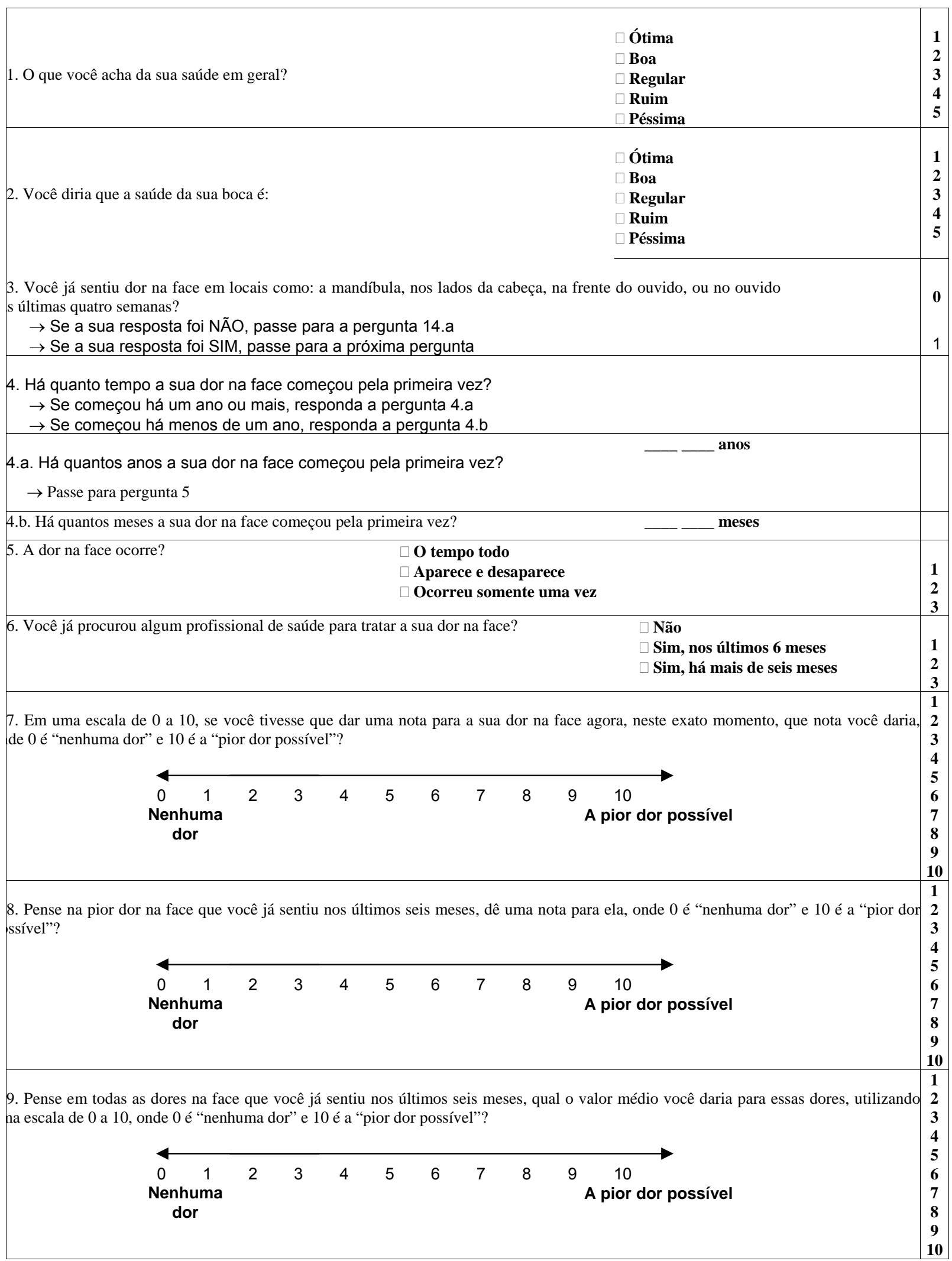


10. Aproximadamente quantos dias nos últimos 6 meses você esteve afastado de suas atividades diárias como: trabalho, cola e serviço doméstico, devido a sua dor na face? dias

11. Nos últimos 6 meses, o quanto esta dor na face interferiu nas suas atividades diárias, utilizando uma escala de 0 a 10 , onde 0 é $\mathbf{2}$ enhuma interferência” e 10 é “incapaz de realizar qualquer atividade”?

$\begin{array}{cccccccccccc}\begin{array}{c}\text { Nenhuma } \\ \text { interferência }\end{array} & 2 & 3 & 4 & 5 & 6 & 7 & 8 & 9 & \begin{array}{l}10 \\ \text { Incapaz de realizar } \\ \text { qualquer atividade }\end{array}\end{array}$

12. Nos últimos 6 meses, o quanto esta dor na face mudou a sua disposição de participar de atividades de lazer, sociais e familiares, onde $\mathbf{2}$ é “nenhuma mudança” e 10 é “mudança extrema”?

$\begin{array}{ccccccccccccc}0 & 1 & 2 & 3 & 4 & 5 & 6 & 7 & 8 & 9 & \begin{array}{l}10 \\ \text { Mudança } \\ \text { extrema } \\ \text { menhuma }\end{array}\end{array}$

13. Nos últimos 6 meses, o quanto esta dor na face mudou a sua capacidade de trabalhar (incluindo serviços domésticos), onde 0 é $\mathbf{2}$ enhuma mudança” e 10 é “mudança extrema”?

\begin{tabular}{ccccccccccccc}
\hline $\begin{array}{c}\text { Nenhuma } \\
\text { mudança }\end{array}$ & 2 & 3 & 4 & 5 & 6 & 7 & 8 & 9 & $\begin{array}{c}10 \\
\text { Mudança } \\
\text { extrema }\end{array}$
\end{tabular}

14.a. Alguma vez a sua mandíbula já ficou travada de uma forma que você não conseguiu abrir totalmente a boca?

$\rightarrow$ Se você NUNCA teve travamento da mandíbula, passe para a pergunta 15.a

$\rightarrow$ Se você JÁ TEVE travamento da mandíbula passe para a próxima pergunta

14.b. Este travamento da mandíbula foi grave a ponto de interferir com a sua capacidade de mastigar?

15.g. Você sente desconfortável ou diferente a forma como os seus dentes se encostam?

17.a. Você teve recentemente alguma pancada ou trauma na face ou na mandíbula?

$\rightarrow$ Se a sua resposta foi NÃO, passe para a pergunta 18

$\rightarrow$ Se a sua resposta foi SIM, passe para a próxima pergunta

17.b. A sua dor na face já existia antes da pancada ou trauma?

19. Quais atividades a sua dor na face ou problema na mandíbula impedem, limitam ou prejudicam?

\begin{tabular}{|c|c|c|}
\hline a. Mastigar & $\begin{array}{l}0 \text { g. Atividade sexual } \\
1\end{array}$ & $\begin{array}{l}\mathbf{0} \\
\mathbf{1} \\
\end{array}$ \\
\hline b. Beber (tomar líquidos) & \begin{tabular}{l|l}
0 & h. Limpar os dentes ou \\
1 & face
\end{tabular} & $\begin{array}{l}\mathbf{0} \\
\mathbf{1}\end{array}$ \\
\hline c. Fazer exercícios físicos ou ginástica & $\begin{array}{l}0 \text { i. Bocejar (abrir a boca } \\
1 \text { lando está com sono) }\end{array}$ & $\begin{array}{l}\mathbf{0} \\
\mathbf{1} \\
\end{array}$ \\
\hline d. Comer alimentos duros & \begin{tabular}{l|l}
0 & $j$. Engolir \\
1 & \\
\end{tabular} & $\begin{array}{l}\mathbf{0} \\
\mathbf{1}\end{array}$ \\
\hline e. Comer alimentos moles & \begin{tabular}{l|l}
0 & $k$. Conversar \\
1 & \\
\end{tabular} & $\begin{array}{l}\mathbf{0} \\
\mathbf{1}\end{array}$ \\
\hline f. Sorrir ou gargalhar & \begin{tabular}{l|l}
0 & l. Ficar com o rosto \\
1 & rmal: sem a aparência \\
dor ou triste
\end{tabular} & $\begin{array}{l}\mathbf{0} \\
\mathbf{1}\end{array}$ \\
\hline
\end{tabular}


20. Nas últimas quatro semanas, o quanto você tem estado angustiado ou preocupado:

\section{Nem Um Pouco Um ModeradamenteMuitoExtremamente}

(0) ?ouco

(2)

(3)

(4)

(1)

a. Por sentir dores de cabeça

b. Pela perda de interesse ou prazer sexual

c. Por ter fraqueza ou tontura

d. Por sentir "aperto no peito" ou no coração

e. Pela sensação de falta de energia ou lentidão

Nas últimas quatro semanas, o quanto você tem estado angustiado ou Nem eocupado:

f. Por ter pensamentos sobre morte ou relacionados ao ato de orrer

g. Por ter falta de apetite

h. Por chorar facilmente

i. Por culpar-se pelas coisa que acontecem ao seu redor

j. Por sentir dores na parte inferior das costas eocupado:

k. Por sentir-se só

1. Por sentir-se triste

m. Por preocupar-se muito com as coisas

n. Por não sentir interesse pelas coisas

o. Por ter enjôo ou problemas no estômago

Nas últimas quatro semanas, o quanto você tem estado angustiado ou Nem eocupado:

anto você tem estado angustiado ou Nem

p. Por ter músculos doloridos

q. Por ter dificuldade em adormecer

r. Por ter dificuldade em respirar

s. Por sentir de vez em quando calor ou frio

t. Por sentir dormência ou formigamento em partes do corpo Nas últimas quatro semanas, o quanto você tem estado angustiado ou Nem Um Pouco Um Moder eocupado:

(0) Pouco

(0) ?ouco

(1)

$\square$

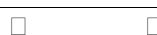

(2)

(3)

(2) (3)

(4)

\begin{tabular}{|c|c|c|}
\hline$\square$ & $\square$ & $\square$ \\
\hline$\square$ & $\square$ & $\square$ \\
\hline$\square$ & $\square$ & $\square$ \\
\hline$\square$ & $\square$ & $\square$ \\
\hline$\square$ & $\square$ & $\square$ \\
\hline
\end{tabular}

damenteMuitoExtremamente

$\square \quad \square \quad \square$

$\square \quad \square$

(4)

$\square$

$\square \quad \square$

$\square$

$\square$
$\square$
$\square$
$\square$
$\square$
(4)

u. Por sentir um "nó na garganta"

$v$. Por sentir-se desanimado sobre o futuro

$\square \quad \square \quad \square$

w. Por sentir-se fraco em partes do corpo

x. Pela sensação de peso nos braços ou pernas

y. Por ter pensamentos sobre acabar com a sua vida

z. Por comer demais

$\square \quad \square \quad \square \quad \square$

$\begin{array}{lc}\square & \square \\ \square & \square \\ \square & \square \\ \square & \square\end{array}$
eocupado:

$\square \quad \square$

$\square$

$\square$

$\square$

(3)

(4)

$\square$
$\square$
$\square$
$\square$
$\square$
(4)

.

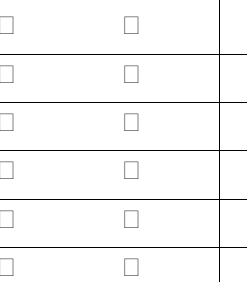

\begin{tabular}{|c|c|c|c|c|c|}
\hline $\begin{array}{l}\text { Nas últimas quatro semanas, o quanto você tem estado ang } \\
\text { eocupado: }\end{array}$ & $\begin{array}{l}\text { Um } \\
\text { (0) }\end{array}$ & $\begin{array}{r}\text { Um } \\
\text { ?ouco } \\
\text { (1) }\end{array}$ & (2) & (3) & (4) \\
\hline aa. Por acordar de madrugada & $\square$ & $\square$ & $\square$ & $\square$ & $\square$ \\
\hline bb. Por ter sono agitado ou perturbado & $\square$ & $\square$ & $\square$ & $\square$ & $\square$ \\
\hline cc. Pela sensação de que tudo é um esforço ou sacrifício & $\square$ & $\square$ & $\square$ & $\square$ & $\square$ \\
\hline
\end{tabular}




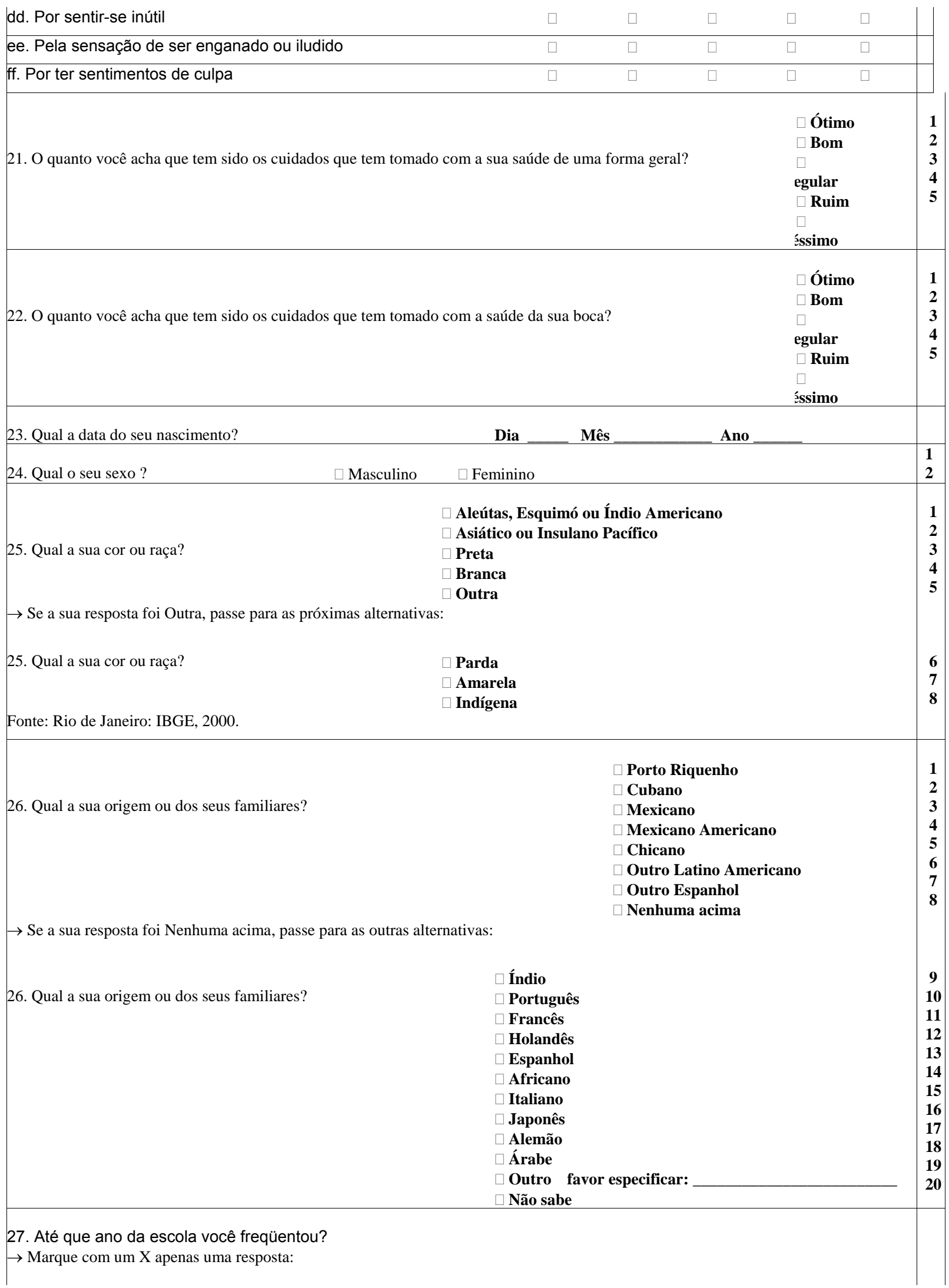




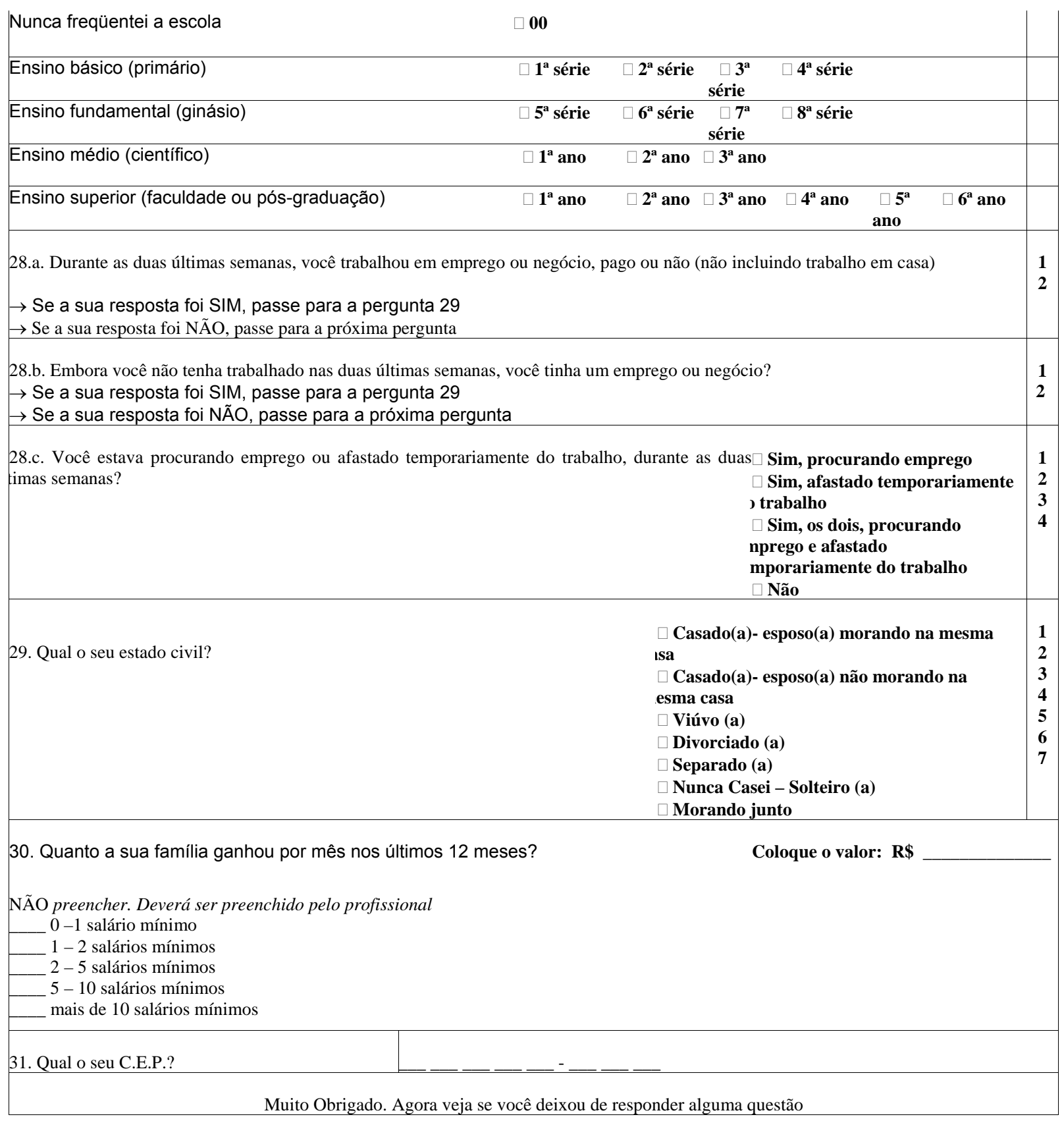




\section{ANEXO 5}

\section{QUESTIONÁRIO McGILL}

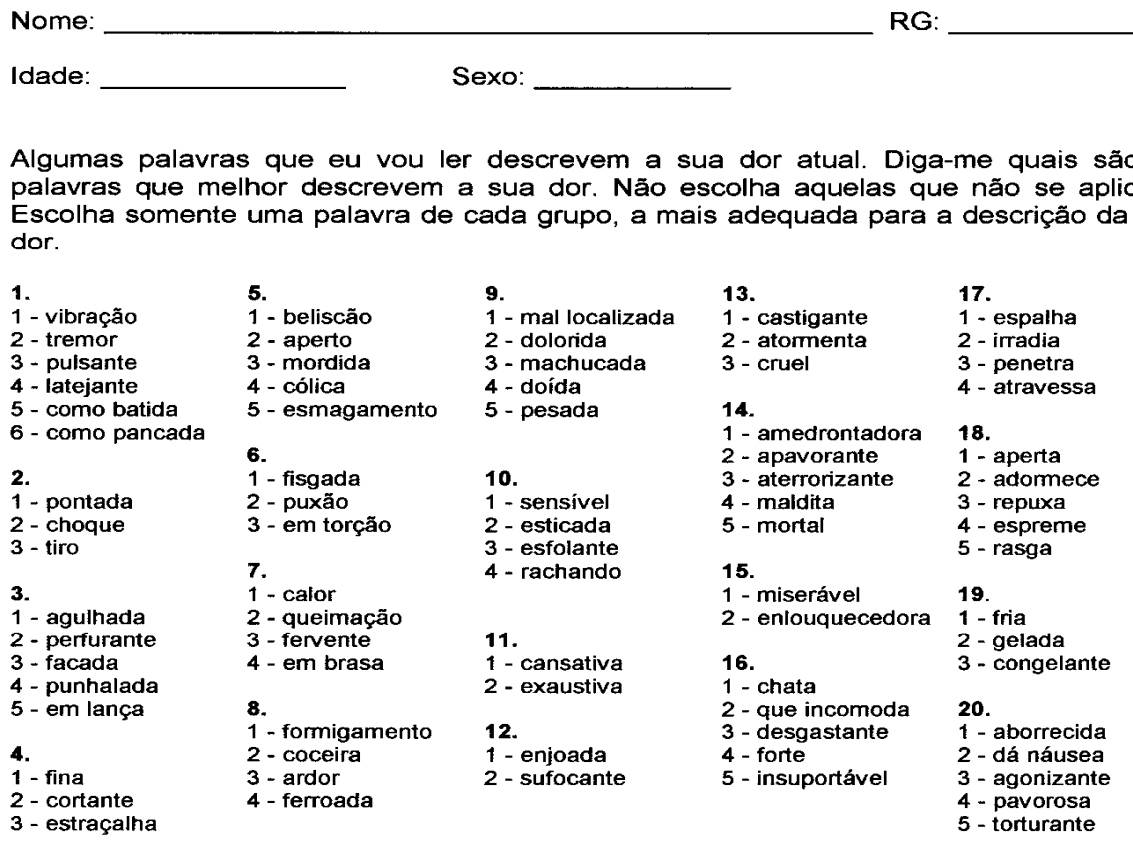

Nümero de Descritores

Sensorial

Afetivo

Avaliativo

Miscelânea

TOTAL
Índice de dor

Sensorial

Afetivo

Avaliativo

Miscelânea

TOTAL 


\section{ANEXO 6}

SITUAÇÃO PERIODONTAL - INDICADORES DE DOENGA

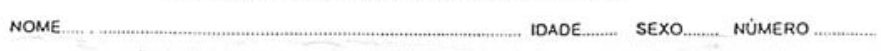

DATA INICIAL REAVALIAÇÁ CONTROLE

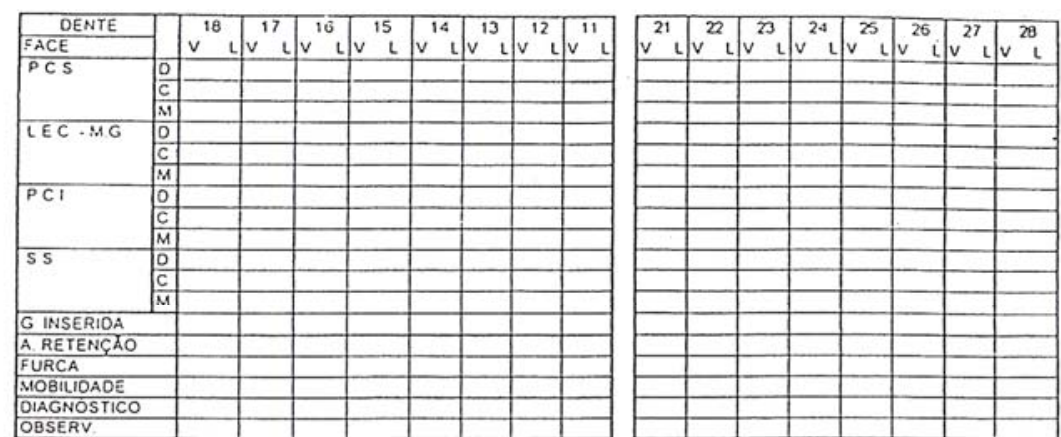

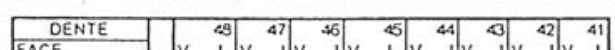
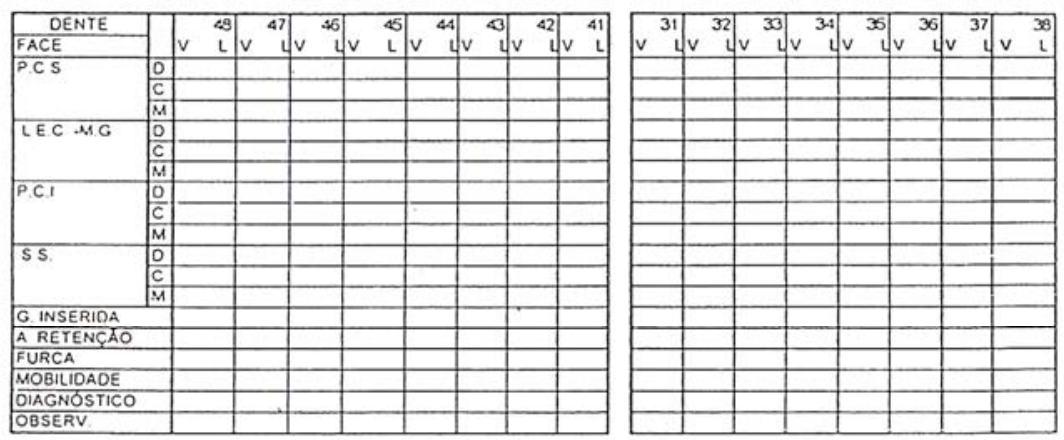

OBSERVAÇOES:

CUIDADOS ESPECIAIS:

PLACA :

CALCULO

DIAGNÓSTICO

NB A. Quando houver crescimento gengival o valor LEC - MG deverd ser negativo

B. Coluna de diagnóstico - CONSULTAR RADIOGRAFIAS

- naso ha perda de inserşajo: $G$ (genghtate). c (cronica). a (aguca)

- ha perda de inserça: P.L perda horizontal ate $1 / 3$ do comprimento da raz

P.G perda mairr que $1 / 3$ do compnmento da ra:

P.C. detentos ossecs angulares - crateras interdentars

bolsas intra bsseas 


\section{ANEXO 7}

\section{AVALIAÇÃO DE SENSIBILIDADE}

Percepção de dormência:

1. Quão intensa é sua dormência:

Sem dormência

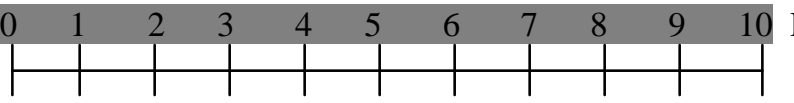

Dormência mais intensa possível

2. Qual das frases melhor descrevem a ocorrência de dormência (sinalize apenas uma):

( ) Eu constantemente sinto dormência.

( ) Eu freqüentemente sinto dormência.

( ) Eu eventualmente sinto dormência.

( ) Eu não sinto dormência.

3. Informe quão desagradável é sua dormência:

Não é desagradável

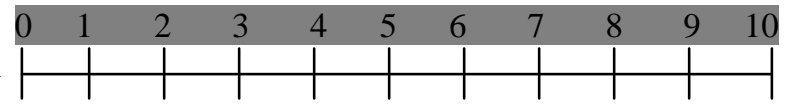

A mais desagradável imaginável

Disestesia:

1. Quão intensa é sua dor:

Sem dor

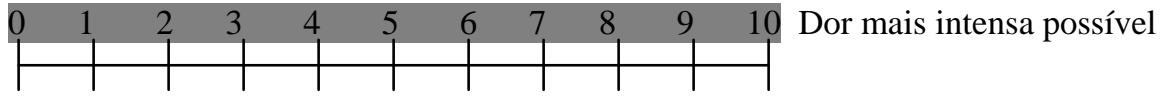

2. Qual a freqüência de sua dor: não tem dor ( ) eventualmente tem dor ( ) freqüentemente tem dor ( ) tem dor constante ( )

Sensibilidade da face:

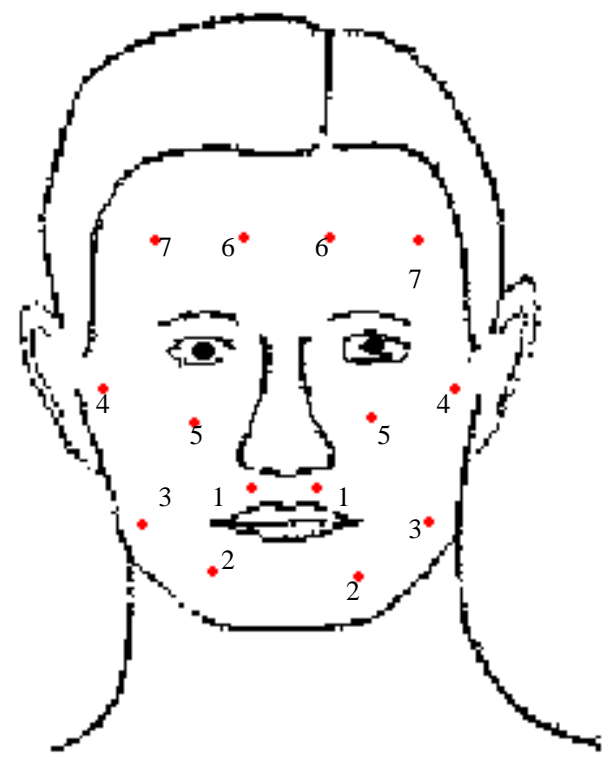

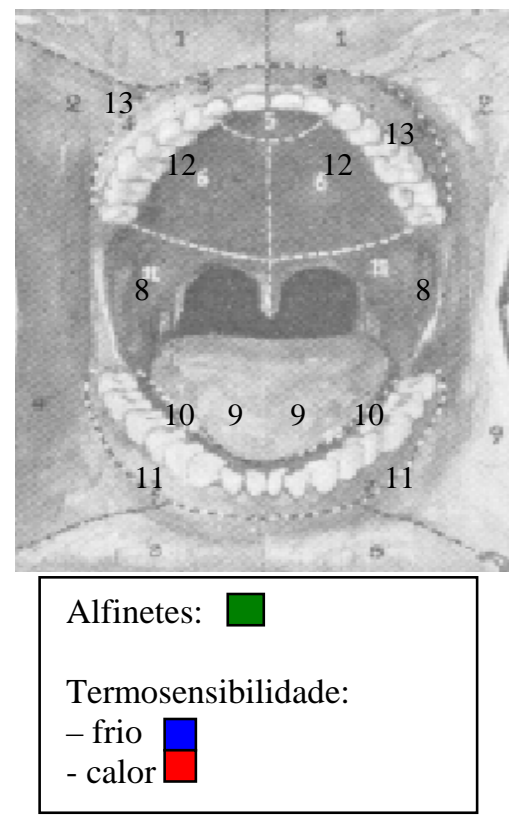

(Siqueira et al.,2006) 


\section{REFERÊNCIAS}

Adeghate $\mathrm{E}$, Schattner $\mathrm{P}$, Dunn E. An update on the etiology and epidemiology of Diabetes Mellitus. Ann NY Acad Sci. 2006;1084 :1-29.

Albandar JM, Rams TE. Global epidemiology of periodontal diseases: an overview. Periodontology2000. 2002;29:7-10.

American Academy of Orofacial Pain. Fourth Edition. R de Leeuw (ed). Orofacial Pain: Guidelines for Assessment, Diagnosis, and Management 2008: Quintessence.

American Diabetes Association. Diagnosis and Classification of Diabetes Mellitus. Diabetes Care. 2007;30Suppl1:S42-S7.

Anbar M, Gratt BM. Role of nitric oxide in the physiopathology of pain. J Pain Symptom Manage. 1997;14:225-54.

Andersen S, Worm-Pedersen J. The prevalence of persistent pain in Danish population. Pain (Suppl). 1987;4:332.

Ainamo J, Bay I. Problems and proposals for recording gingivitis and plaque. International Dental Journal. 1975;25:229-35.

Blasberg B, Greenberg MS. Orofacial Pain. In: Greenberg MS; Glick M. Burket's Oral Medicine. 10th ed. Philadelphia: BC Decker Inc; 2003. p.307-40.

Bergdahl J, Anneroth G. Burning Mouth Syndrome: Literature review and model for research and management. J Oral Pathol Med. 1993;22:433-8.

Boulton AJM. Management of Diabetic Peripheral Neuropathy. Clin Diabetes. 2005;23:9-15. 
Camparis CM, Siqueira JTT. Sleep bruxism: clinical aspects and characteristics in patients with and without chronic orofacial pain. Oral Surg Oral Med Oral Pathol Oral Radiol Endod. 2006;101:188-93.

Collin H-L, Niskanen L, Matti U, Jári T, Collin P, Coivisto A-M, Viinamäki H, Meurman $\mathrm{JH}$. Oral symptoms nad signs in elderly patients with type 2 diabetes mellitus: a focus on diabetic neuropathy. Oral Surg Oral Med Oral Pathol Oral Radiol Endod. 2000;90:299-305.

Coronho V, Petroianu A, Santana EM, Pimenta LG. Tratado de endocrinologia e cirurgia endócrina. Ed. Guanabara Koogan: Rio de Janeiro; 2001.

Costa LA, Canani LH, Lisbôa HRK, Tres GS, Gross JL. Aggregation of features of the metabolic syndrome is associated with increased prevalence of chronic complications in type 2 diabetes. Diabet Med. 2004;21:252-55.

Cuffari L, Siqueira JTT, Nemr K, Rapaport A. Pain complaint as the first symptom of oral cancer: a descriptive study. Oral Surg Oral Med Oral Pathol Oral Radiol Endod. 2006;102:56-61.

De Leeuw R, Boering G, Stegenga B, de Bont LGM. Clinical signs of TMJ osteoarthrosis and internal derangement 30 years after nonsurgical treatment. J Orofac Pain. 1994;8:18-24.

Dodds MWJ, Yeh CK, Johnson DA. Salivary alterations in type 2 diabetes mellitus and hypertension. Community Dent Oral Epidemiol. 2000;28:373-81.

Eliev E, Kamran B, Schaham R, Czerninski R, Gracely RH, Benoliel R. Evidence of chorda tympani dysfunction in patients with burning mouth syndrome. J Am Dent Assoc. 2007;138(5):628-3.

Gagliardi ART. Neuropatia diabética periférica. J Vasc Br. 2003;2:67-74.

Gao S, Wang Y, Wang Z. Assessment of trigeminal somatosensory evoked potentials in burning mouth syndrome. Chin J Dent Res. 2000;3:40-6.

Goes PSA (2001). The prevalence, severity and impact of dental pain in Brazilian schoolchildren and their families. Department of Epidemiology and Public Health. University College London. University of London. PhD Thesis. 
Gorsky M, Silverman Jr S, Chinn H. Clinical characteristics and management outcome in the burning mouth syndrome. An open study of 130 patients. Oral Surg Oral med Oral Pathol. 1991;72:192-5.

Grushka M. Burning mouth syndrome:pain desorder remains difficult to treat. Ont Dent. 1987;64:26-30.

Grushka M, Sessle BJ. Burning mouth syndrome. Dent Clin North Am. 1991; 35:171-84.

Hu JW, Tsai CM, Bakke M, Seo K, Tambeli CH, Vernon H, Bereitter DA, Sessle BJ. Deep craniofacial pain: Involvement of trigeminal subnucleus caudalis and its modulation. In: In: Jensen TS, Turner JA, Wiesenfeld-Hallin Z. editors. Proceedings of the 8th World Congress on Pain, Progress in Pain Research and Management. vol 8, Seattle: IASP Press; 1997. p.497-506.

IASP - International Association for the study of Pain (Subcommittee Taxonomy - Classification of chronic pain:descriptions of chronic pain syndromes and definitions of pain terms. 2ed. Seattle. IASP press, 1994.p 209-14.

John MT, Miglioretti DL, LeResche L, Von Korff M, Critchlow CW. Widespread pain as a risk factor for dysfunctional temporomandibular disorder pain. Pain 2003;102:257-63.

Kelkar P. Diabetic neuropathy. Semin Neurol. 2005;25:168-173.

Kennedy PGE, Grinfeld E, Gow JW. Latent Varicella-zoster virus in human dorsal root ganglia. Virology. 1999;258:451-4.

Kosminsky M, Lucena LBS, Siqueira JTT, Pereira Junior FJ, Goes PSA. Adaptação cultural do Questionário Research Diagnostic Criteria for Temporomandibular Disorders: Axis II para o Português. JBC - Jornal Brasileiro de Clínica Odontológica Integrada. 2004;8:51-61.

Kurogi F, Okada M, Siqueira SRDT, Teixeira MJ, Siqueira JTT. Evaluation of the sensation in patients with trigeminal post herpetic neuralgia. Journal of Oral Pathology and Medicine. 2007;36:247-350. 
Lamote RH. Neurophisilogical mechanisms of cutaneous secondary hyperalgesia in the primate. In: Wills WD. Hyperalgesia and allodynnia. New York: Raven; 1992;175-85.

Lauritano D, Spadari F, Formaglio F, Zambellini Artini M, Salvato A. [Etiopathogenic, clinical-diagnostic and therapeutic aspects of the burning mouth syndrome. Research and treatment protocols in a patient group]. Minerva Stomatol. 1998;47:239-51.

Lauria G, Majoara A, Borgna M, Lombardi $P$ et at. Trigeminal small-fiber sensory neuropathy causes burning mouth syndrome. Pain. 2005;115:332-37.

LeResche L, Dworkin SF, Saunders K, Von Korff M, Barlow W. Is postmenopausal hormone use a risk factor for TMD? J Dent Res. 1994; 73:186.

Lipton JA, Ship JA, Larach-Robinson D. Estimated prevalence and distribuition of reported orofacial pain in the United States. J Am Dent Assoc. 1993; 124:115-21.

Löe $\mathrm{H}$ et al. The natural history of periodontal disease in man. The rate of periodontal destruction before 40 years of age. J Periodontol. 1978;49:607-20.

Maltsman-Tseikhin A, Moricca P, Niv D. Burning mouth syndrome:will better understanding yield better management? Pain Practice. 2007;7:151-62.

Marques APO, Arruda IKG, Leal MCC, Santo ACGE [on-line]. Envelhecimento, obesidade e consumo alimentar em idosos. Rev Bras Geriatr Gerontol. [cited 2008] Available from http://www.unati.uerj.br/tse/scielo.php?script=sci_abstract\&pid=S1809$98232007000200008 \&$ lng $=$ pt\&nrm=iso

Manfredi M, McCullogh MJ, Vescovi P, Al Kaarawi ZM, Porter SR. Update on diabetes mellitus and related oral diseases. Oral Diseases. 2004;10:187-200.

McNeill C. Temporomandibular disorders: Guidelines for classification, assessment, and management. The American Academy of Orofacial Pain. Quintessence, Chicago, 1993. 
Mealey BL, Rethman MP. Periodontal disease and Diabetes mellitus. Bidirectional relationship. Dental Today. 2003;22(4):107-13.

Mealey BL, Rose LF. Diabetes mellitus and inflammatory periodontal diseases. Curr Opin Endocrinol Diabetes Obes. 2008;15:135-141.

Merskey H, Bogduk N. Classification of chronic pain. 2a ed. Seattle: IASP Press; 1994.

Nasri C, Okada M, Formigoni G, Teixeira MJ, Heir G, Siqueira JTT. Burning Mouth Syndrome: Clinical characteristics of a Brazilian sample. Clinics. 2007; 62:561-6.

Okeson JP. Orofacial Pain: Guidelines for Assessment, Diagnosis and Management. Chicago: Quintessence, 1996.

Okeson JP. Dores Bucofaciais de Bell. 6a ed. São Paulo: Quintessence; 2006.

Pereira Junior, FJ. Critérios de Diagnóstico para a pesquisa das disfunções temporomandibulares (RDC/TDM): tradução oficial para Língua Portuguesa. JBC - Jornal Brasileiro de Odontologia Clínica. 2004; 8:384-395.

Petersen PE. Tobacco and oral health-the role of WHO. Oral Health Prev Dent. 2003;1:309-15.

Pimenta CAM, Teixeira MJ. Proposta de adaptação do questionário de dor McGill para a Língua Portuguesa. Rev Esc Enf USP. 1996;30:473-83.

Projeto SB Brasil 2003. Condições de saúde bucal da população brasileira 2002-2003: resultados pricipais. Ministério da saúde, Secretaria de Atenção à Saúde, Departamento de Atenção Básica . Brasíla. Ministério da Saúde. 2005.

Ren K, Dubner R. Descending modulation in persistent pain: an update. Pain. 2002;100:1-6. 
Scala A, Checchi M, Montevecchi M, Marini I. Update on burning mouth syndrome overview and patient managemt. Crit Rev Oral Biol Med. 2003:14: 275-91.

Scrivani SJ, Keith DA, Kaban LB. Tempormandibular disorders. N Eng J Med. 2008;359:2693-2705.

Secretaria de Estado da Saúde de São Paulo. Condições de Saúde Bucal no Estado de São Paulo em 2002. São Paulo, 2002.

Sessle BJ. Pain. In: Oral Biology. EUA: Mosby Company; 1981. p.3-28.

Sessle BJ. Peripheral and central mechanisms of orofacial pain and their clinical correlates. Min Anestesiol. 2005;71(4):117-36.

Shinkai RSA, Hatch JP, Cornell JE, Yeh CK. Intraoral tactile sensitivity in adults with diabetes. Diabetes Care. 2004;27:869 -73.

Siqueira JTT, Teixeira MJ. Dor Orofacial. Diagnóstico, Terapêutica e Qualidade de Vida. Curitiba: Editora Maio; 2001.

Siqueira JTT, Lin HC, Nasri C, Siqueira SR, Teixeira MJ, Heir G, Valle LB. Clinical study of patients with persistent orofacial pain. Arq Neuropsiquiatr. 2004;62:988-96.

Siqueira SRDT, Nóbrega JCM, Teixeira MJ, Siqueira JTT. Olfactory threshold increase in trigeminal neuralgia after balloon compression. Clin Neurol and Neurosurg. 2006;108:721-5.

Siqueira SR, da Nobrega JC, Teixeira MJ, de Siqueira JT. Masticatory problems after balloon compression for trigeminal neuralgia: a longitudinal study. J Oral Rehabil. 2007;34:88-96.

Spruce MC, Potter J, Coppini DV. The pathogenesis and management of painful diabetic neuropathy: a review. Diabet Med. 2003;20:88-98. 
Staud R, Koo E, Robinson ME, Price DD. Spatial summation of mechanically evoked muscle pain and painful after sensations in normal subjects and fibromyalgia patients. Pain 2007;130:177-87.

Stohler CS. Muscle-related Temporomandibular disorders. J Orofacial Pain. 1999;13:273-84.

Svensson P, Bjerring P, Arendt-Nielsen L, Kaaber S. Sensory and pain thresholds to orofacial argon laser stimulation in patients with chronic burning mouth syndrome. Clin J Pain.1993;9:207-15.

The International Classification of Headache Disorders: 2nd edition. Cephalalgia. 2004;24 Suppl 1:9-160.

Teixeira MJ. Estudo Master em dor. $1^{\circ}$ SIMBIDOR;1994;São Paulo.

Teixeira MJ, Marconi RM, Rocha RO, Figueiró JB. Epidemiologia clínica da dor. Rev Med. 1999;78:36-54.

Teixeira MJ. Fisiopatologia da nocicepção e da supressão da dor. In: Siqueira JTT, Ching LH, editores. Dor Orofacial / ATM - Diagnóstico, terapêutica e qualidade de vida. Curitiba: Editora Maio; 2001. p.68-86.

Travell J, Simon D. Myofascial pain and dysfuncion: The trigger point manual. Baltimore: Williams, Wilkins; vol 2, 1992.

Unruh AM. Gender variations in clinical pain experience. Review article. Pain. 1996;65:123-67.

Vernillo AT. Diabetes mellitus: relevance to dental treatment. Oral Surg Oral Med Oral Pathol Oral Rad Endod. 2001;91:263 - 70.

Von Korff A, Dworkin SF, Le Resche L, Kruger A. An epidemiologic comparison of pain complaints. Pain. 1988;32:173-83. 
Von Korff A. Health services research and temporomandibular pain. In: Sessle BJ, Bryant PS, Dionne RA, editors. Temporomandibular Disorders and Related Pain Conditions, Progress in Pain Research and Management vol 4. Seattle IASP Press; 1995. p.227-36.

Watkins LR, Maier SF. The pain of the being sick: Implications of Immune-toBrain communication for understanding pain. Ann Rev Psychol. 2000;51:2957.

White Jr JR et al. Clarifying the role of insulin in type 2 Diabetes management. Clinical Diabetes. 2003;21:14-21.

Wild S, Roglic G, Green A, Sicree R, King H. Global prevalence of Diabetes. Diabetes Care. 2004;27:1047-53.

Xie YF, Zhang S, Chiang CY, Hu JW, Dostrovsky JO, Sessle BJ. Involvement of glia in central sensitization in trigeminal subnucleous caudalis (medullary dorsal horn). Brain Behav Immun. 2007;21:634-41.

Yilmaz Z, Renton T, Yangou Y, Zakrzewska J, Chessell IP, Bountra C, Anand $P$. Burning Mouth Syndrome as a trigeminal small fibre neuropathy: Increased heat and capsaicin receptor TRPV1 in nerve fibres correlates with pain score. Journal of Clinical Neuroscience. 2007. On-line.

Zakrzewska JM. Burning Mouth. Assessment and Management of Orofacial Pain. Pain Research and Clinical management. 2002;14:371-84. 